\title{
Desigualdad de los ingresos fiscales en el departamento de Santander (1985-2017)
}

\author{
Inequality of tax revenues in the \\ department of Santander (1985-2017
}

\section{Resumen}

Artículo de investigación.

Fecha de recepción: 15/03/2020

Fecha de devolución: 26/06/2020

Fecha de aceptación: 07/07/2020

Fecha de publicación: 20/07/2020

\section{Betty Cecilia Barajas Ibáñez \\ Investigadora independiente. \\ Málaga (Colombia) \\ ibi1206@hotmail.com}

\section{Julián Augusto Casas Herrera}

Universidad Pedagógica y Tecnológica de Colombia. Tunja (Colombia)

julian.casas01@uptc.edu.co

Para citar este artículo:

Barajas, B. \& Casa, J. (2020). Desigualdad de los ingresos fiscales en el departamento de Santander (1985-2017).. Económicas CUC, 41(2), 211-236. DOI: https://doi.org/10.17981/econcuc.41.2.2020.Econ.4
La descentralización pública en Colombia fue una de las reformas organizada mediante la aplicación del principio de libertad económica, lo cual buscaba revertir el proceso de centralización que comenzó a partir de la constitución de 1886. Así entonces, este documento analiza, a partir del índice de Theil y el coeficiente de Gini, el grado de desigualdad de los ingresos fiscales de los municipios de Santander para el periodo 1985 a 2017, lo que permitirá explicar la contribución de la descentralización fiscal en la reducción de las disparidades intermunicipales y provinciales. Los resultados indican, por un lado, a pesar de haberse reducido la desigualdad en el marco del proceso de descentralización fiscal, aún persisten marcadas disparidades entre los pequeños municipios del departamento; y por el otro, que el descenso de la desigualdad se logró, especialmente, por las trasferencias del gobierno central y la dinámica económica de los grandes municipios. Lo cual permitió concluir que la descentralización pretendía reducir las disparidades regionales, al trasladar el poder de decisión y ejecución de políticas públicas a cargo del nivel central hacia los territorios.

Palabras clave: Descentralización fiscal; desigualdad de ingresos; transferencias; Gini; Theil

\begin{abstract}
Public decentralization in Colombia was one of the reforms organized through the application of the principle of economic freedom, which sought to reverse the process of centralization that began with the 1886 constitution. Thus, this document analyzes, based on the index of Theil and the Gini coefficient, the degree of inequality of the fiscal income of the municipalities of Santander for the period 1985 to 2017 , which will explain the contribution of fiscal decentralization in reducing inter-municipal and provincial disparities. The results indicate, on the one hand, despite the reduction in inequality within the framework of the fiscal decentralization process, marked disparities still persist among the small municipalities of the department; and on the other hand, that the decrease in inequality was achieved, especially, by transfers from the central government and the economic dynamics of the large municipalities. This made it possible to conclude that decentralization was intended to reduce regional disparities, by transferring the power of decision and execution of public policies from the central level to the territories.

Keywords: Fiscal decentralization; income inequality; transfers; Gini; Theil
\end{abstract}




\section{INTRODUCCIÓN}

En las dos últimas décadas del siglo XX y en lo corrido del presente, en Colombia se adelantaron distintas reformas, dirigidas a ajustar el andamiaje institucional a lineamientos promercado. Los artículos 26, 58, 226, 227 y 333 de la Constitución Política (CP, 1991) estipulan los principios de libertad económica. La descentralización pública fue una de las reformas, organizada mediante la aplicación de tales principios. Esta pretendió revertir el proceso de centralización por el que atravesó el país, desde la constitución de 1886 hasta la de 1991, para darle autonomía a las entidades municipales y departamentales. Así, la administración pública tendría una relación más cercana con los ciudadanos de los territorios, ya que supuso que estos son quienes conocen las fortalezas y debilidades de su territorio.

Para superar una de las debilidades de las regiones (la desigualdad), se implementó la descentralización con el objetivo de reducir las brechas socioeconómicas (Guerrero, 2014). No obstante, el gobierno central no dejó a la deriva la consecución de lo anterior, ya que ató las actuaciones de las entidades territoriales a los lineamientos de los planes de desarrollo, que serían evaluadas a través de indicadores (Restrepo, 2006).

En consecuencia, la descentralización se erigió como una realidad (casi indiscutida) en el país. En ese sentido, lo que podía ser objeto de discusión era la forma de implementación en las entidades territoriales. Ante ello, hubo dos corrientes de pensamiento, distanciadas por el modo como entienden, interpretan y explican el funcionamiento de los procesos de descentralización y sus resultados.

La primera cree en la eficiencia del mercado en la provisión de bienes públicos, así como en la distribución de la riqueza. Por ello, el Estado debe hacer las reformas necesarias para garantizar eficiencia y crecimiento económico. Además, las regiones deben asumir una política activa basada en la participación ciudadana, que traerá mayor bienestar social (Hernández y Chumaceiro, 2018).

La segunda considera que los procesos de descentralización modifican la relación entre el sector privado y el Estado, alterando el papel del segundo a favor del primero. Esto se evidencia en medidas como el manejo de lo público por parte de lo privado bajo los principios del mercado (Giraldo, 2005). Valga decir que la segunda corriente no se opone a la descentralización pública, solo que considera extraño que la primera no le dé importancia a los fallos del mercado, los cuales generan ineficiencia y profundizan la desigualdad.

Desde esa línea de pensamiento, surgió la siguiente pregunta como motivación para la realización del documento: ¿Cuál ha sido el grado de desigualdad de los ingresos fiscales de los municipios del departamento de Santander, para el periodo comprendido entre 1985 a 2017, en el marco del proceso de la descentralización fiscal?

El documento tiene una estructura capitular diseminada en cuatro secciones, aparte de la introducción. En la segunda, se presenta una contextualización de algunos elementos teóricos, normativos, políticos y económicos de la descentralización pública en Colombia. En la tercera, se presenta la metodología utilizada para el cálculo del coeficiente de Gini y el índice de Theil que permiten determinar las disparidades intermunicipales y provinciales. En la cuarta, se analizan los resultados obtenidos. Finalmente, se realizan unas conclusiones tendientes a mostrar la prospectiva para futuras investigaciones sobre la temática de este artículo. 


\section{Sobre la descentralización}

los procesos de descentralización fiscal se apoyan en los trabajos de Samuelson ${ }^{1}$ (1954), Tiebout (1956), Musgrave ${ }^{2}$ (1959), $\operatorname{Arrow}^{3}$ (1969) de los que se desprende el teorema de la descentralización. El teorema expresa la incapacidad del gobierno central de gobernar adecuadamente en los diversos territorios de un país por la multiplicidad de preferencias de los habitantes (Oates, 1972).

Para corregir dicha incapacidad, el teorema sugiere que el gobierno central delegue o descentralice en los gobiernos locales el suministro de bienes sociales básicos (Hernández y Barreto, 2018). Para efectuar este proceso, debe haber una transferencia de recursos fiscales del gobierno central hacia los territorios para que atiendan la provisión de los bienes públicos requeridos (Oates, 1972).

Es pertinente señalar que la descentralización está presente desde hace dos siglos en la mayoría de los países del mundo (Sagawe, 2006) y se interpreta como una traslación del poder de decisión y ejecución de políticas públicas a cargo del Estado a nivel central en los territorios. Sin embargo, es necesario establecer las responsabilidades que se mantienen a nivel central y las que no ${ }^{4}$.

Además, detrás del concepto de descentralización está implícita la existencia de estructuras político-administrativas de distintos niveles que asumen funciones específicas y la distribución de recursos para atenderlas, bajo el criterio de eficiencia económica. Este criterio implica evaluar la actuación de las distintas estructuras públicas (central y local), desde la perspectiva del ingreso y del gasto (Rodríguez y Adala, 2005; Paredes-Chacín, 2017).

En ese sentido, el estudio de los diferentes niveles de gobierno se relaciona con lo que se denomina federalismo fiscal. Oates (1972) define un sistema federal como "un sector público con niveles centralizados y descentralizados de gobierno en los cuales cada nivel decide los servicios a prestar, primordialmente con base en lo que los ciudadanos bajo su jurisdicción demandan” (p. 17). No obstante, para Flores (2002) el análisis del federalismo fiscal sobre la descentralización puede aplicarse a otras formas de gobierno que no sean federales, puesto que solo basta con que exista un sector público que posea diferentes niveles con capacidad de tomar y ejecutar decisiones.

Frège (1986) entiende la descentralización, por un lado, como un proceso administrativo que optimiza la eficiencia en la organización del Estado y, por el otro, como un proceso político que asigna una repartición territorial de las responsabilidades, respetando los lineamientos del Estado. En síntesis, la descentralización transfiere competencias y recursos del gobierno central hacia las administraciones municipales.

Las iniciativas descentralizadoras han sido abordadas, generalmente, desde dos visiones. Por un lado, está la que desconfía del Estado y, por ende, privilegia el mecanismo de mercado como garante de la eficiencia en la asignación y distribución de los recursos, a los diferentes agentes económicos, para alcanzar el máximo bienestar social. En la

\footnotetext{
1 Definió la naturaleza de los bienes públicos.

2 Propuso las funciones del gobierno en relación con la distribución de ingresos, la corrección de las fallas del mercado y la estabilización macroeconómica.

3 Conceptualizó los papeles de los sectores público y privado.

4 Las principales responsabilidades trasladadas son la provisión de: educación, salud, programas de reducción de pobreza, caminos locales, vivienda, servicio de agua y alcantarillado (Fondo Monetario Internacional-FMI, 2001; Paz, Harris y Franco, 2016; Casas, 2017).
} 
misma línea de pensamiento, Heilbroner y Milberg (1995) manifiestan que la desigualdad disminuirá y el sistema convergería al equilibrio en largo plazo, siempre y cuando no haya interferencia del Estado. De hecho, esta visión considera que el Estado debe ser neutral, a menos que haya fallas en el mercado o actividades al margen de la ley (Giraldo, 2005; De la Torre, 2018).

Por consiguiente, la descentralización se justifica porque el Estado de Bienestar provocó excesiva burocracia y despilfarro de recursos, generando en la ciudadanía un paternalismo estatal (Gutiérrez, 1990; Rojas, 2016). Lo anterior estimuló una creciente inflación en los 60's del siglo XX debido a las exigencias sociales de los funcionarios. Por ello, el gobierno central debía desregular los mercados para facilitar los flujos de mercancías y de capitales.

Para la otra visión, los procesos de descentralización tienen el propósito de favorecer al sector privado en detrimento del Estado (Giraldo, 2005). No obstante, esta visión no se opone a la descentralización, sino que considera que no se debe tener una confianza absoluta en el mercado, porque sus fallas provocan ineficiencia y profundizan los problemas de inequidad. De hecho, Betancurt (2002) comentan que en Colombia se apostó por el eficientismo económico en detrimento de la equidad. De acuerdo con Restrepo (2006, p. 19) la descentralización es "el resultado de la pugna entre estrategias propias de una multiplicidad de actores económicos, políticos y sociales en unas condiciones históricas específicas: La reestructuración del Estado y la sociedad capitalista”. Lo anterior obedece según Boisier (1987) a:

[...] la propia dinámica centralizadora la que estimula la demanda descentralista que a su vez es empujada por cuestiones y percepciones de desarrollo desigual, de dominación (...) de revitalización de etnias, y culturas, de penetración de espacio regional y local por parte de lo que se ha llamado el poder "meso económico" de las corporaciones transnacionales e incluso de los Estados (pp. 141-142).

A partir de los aspectos señalados de ambas visiones se destaca el papel de la economía pública que sirve para analizar la intervención del Estado dentro de esta. Este análisis se suele enfocar de dos maneras: desde la teoría de los bienes públicos o desde la teoría de la elección pública. De todos modos, ambas aceptan que el Estado debe asumir la provisión de los bienes públicos a toda o una parte de la sociedad.

Desde la teoría de los bienes públicos Tiebout (1956), Musgrave (1959) y Oates (1972) afirman que los bienes públicos locales pueden ser consumidos por los individuos que residen en el lugar donde se proveen. No obstante, para que estos bienes puedan ser consumidos, las entidades descentralizadas deben tener en cuenta que el bien público local revela mejor las preferencias de la población que el bien que ofrece el gobierno nacional (Tiebout, 1956).

De lo anterior se deduce que la relación entre el consumidor del bien público local y el proveedor (el gobierno local) es directa, lo que permite al ciudadano evaluar su disposición a pagar, a través de los impuestos que cancela, sobre la cantidad de bienes que demanda. Esto implica pensar en una posibilidad: la migración, debido a que algunos territorios ofrecen más oportunidades que otros. En consecuencia, si el ciudadano percibe que la relación costo-beneficio (impuestos-servicios) no es favorable, podría migrar. Por ende, la migración podría ser vista como una sanción a la ineficiencia de un gobierno local, haciendo que el ciudadano salga del territorio a otros lugares del país (Guerrero, 2009). 
Ahora bien, la teoría de la elección pública considera al individuo como el responsable de sus decisiones, a través del voto. De hecho, el Banco Mundial (1998) expresa que el proceso de votación es clave para la descentralización, puesto que acerca a los votantes a elegir a los gobernantes que atiendan a las demandas colectivas de los ciudadanos de bienes públicos locales, cumpliendo los objetivos de eficiencia y equidad a nivel nacional (Brennan y Buchanan, 1980).

\section{Descentralización fiscal en Colombia}

Una vez realizada la contextualización teórica, se pasa a destacar algunos elementos normativos, políticos y económicos del proceso descentralizador en Colombia. La Constitución de 1886 definió al país como un Estado centralizado políticamente y descentralizado administrativamente. Así el poder ejecutivo decidía sobre algunas funciones y responsabilidades de departamentos y municipios (v.g. cobro de impuestos).

Lo anterior se mantuvo durante la mayor parte del siglo XX. Sin embargo, a mediados del mismo siglo se avizoró la necesidad de modificar algunos aspectos del proceso de descentralización, a partir de las recomendaciones de Currie (1951) sobre las condiciones socioeconómicas de Colombia.

La principal recomendación, en materia de descentralización, hecha al gobierno central fue ceder a departamentos y municipios una porción del recaudo de los tributos, bajo la condición de que asignaran los recursos, en especial, a educación y salud (Younes, 2012). Lo anterior se estipuló en el Acto Legislativo $\mathrm{N}^{\circ} 1$ de $1968^{5}$, así como en las leyes 33 de 1968 ${ }^{6}, 46$ de 19717, 43 de $1975^{8}$ y 12 de $1986^{9}$ (Hernández y Barreto, 2018).

Sin embargo, la principal reforma de la descentralización fiscal se concretó en 1991 con la nueva Constitución Política y la Ley 60 de 1993, de la que se pasó de un modelo proteccionista a uno de apertura económica (Hernández y Barreto, 2018). Dentro de las generalidades del proceso de descentralización, se puede decir que se compone de tres etapas: administrativa, fiscal y política (Chumaceiro y Hernández, 2012; Reales, 2016).

La administrativa se refiere, según Hernández (2016), a "la radicación de funciones en personas jurídicas diferentes al Estado, especialmente en las colectividades locales, lo que implica su reconocimiento jurídico, y estas pueden ser de carácter territorial o especializado por servicios" (p. 93). La fiscal según Villa (2005) "hace parte de una estrategia para la orientación y movilización de recursos en tal forma que se obtenga un beneficio neto al momento de entregar servicios sociales a una comunidad" (p. 2). Finalmente, la política se fundamenta en que los habitantes de la comunidad deciden al gobernante que toma las decisiones relacionadas con la provisión de bienes públicos de su territorio.

Además, la Constitución de 1991 determinó reglas sobre la cesión, reparto territorial y uso de los recursos fiscales de la nación hacia las regiones. El artículo 209 definió los principios de la función administrativa de la siguiente manera: "igualdad, moralidad,

\footnotetext{
5 Instauró el situado fiscal como una transferencia de la nación a los departamentos, para financiar gastos en educación primaria y salud (Viloria, 2001).

6 Proveyó el fortalecimiento a los fiscos seccionales y municipales.

7 Dio independencia a los municipios para planificar el desarrollo regional y local, así como la prestación de servicios.

8 Empezó a distribuir la participación en materia educativa.

9 Dio normas sobre la cesión de impuesto a las ventas o Impuesto al Valor Agregado a los territorios.
} 
eficacia, economía, celeridad, imparcialidad y publicidad, mediante la descentralización, la delegación y la desconcentración de funciones" (CP, 1991, art. 209). Igualmente, el artículo $356(\mathrm{CP}, 1991)$ autorizó al gobierno para que estableciera el porcentaje de los ingresos corrientes que la Nación cedería a los municipios y departamentos. Además, estableció la destinación específica de los recursos para educación (preescolar, primaria, secundaria y media) y salud (Hernández y Barreto, 2018).

A raíz de los artículos 356 y $357^{10}$ de la Constitución se expidió la Ley 60 (1993), en la que se reglamentó la distribución del situado fiscal y de la participación de departamentos y municipios en: educación (52.5\%), salud (23.8\%), propósito general ${ }^{11}(21.8 \%)$, resguardos indígenas $(0.6 \%)$ y Fondo Nacional de Pensiones de las Entidades Territoriales (FONPET) $(1.3 \%)^{12}$.

En ese sentido, la descentralización transfiere recursos a los territorios de manera condicionada, buscando que con el tiempo realicen un esfuerzo fiscal creciente que ayude a autofinanciar sus principales gastos (Giraldo, 2005). Sin embargo, lo anterior se derivó en un incremento del déficit fiscal, que pasó del 0.8\% del PIB en 1990 al 5.8\% en 1999. Dicho déficit se atribuyó a las transferencias.

A pesar de que la intención es descentralizar, la centralización administrativa del Estado se mantuvo, según Guerrero (2009), ya que la nación percibió "el 82\% de todo el recaudo tributario del país; los departamentos el 6\% y los municipios el 12\% [...], esta es, entre otras razones, por la que, la nación debe transferir a las entidades territoriales parte de sus ingresos" (p. 31). Ante el creciente déficit fiscal, el gobierno expidió la Ley 617 (2000) y la Ley 715 (2001), con el fin de aumentar la base gravable y ampliar las cargas impositivas a los municipios y departamentos. Es decir, estas normativas surgen, porque para el gobierno central los entes territoriales son ineficientes por no aumentar el recaudo de los recursos propios ni por disminuir el grado de dependencia de las transferencias del orden nacional (Tobar, 2011).

La Ley 60 de 1993 (con vigencia hasta el 2001) creó el Sistema General de Participaciones (SGP) con la intención de frenar el crecimiento de las transferencias. Además, en el Acto legislativo 01 (2001) ${ }^{13}$ se "agrupó el situado fiscal y la participación municipal dentro del SGP como una cuenta única y desligó la determinación de las transferencias como una proporción de los ingresos corrientes de la Nación durante siete años" (Hernández y Barreto, 2018, p. 26).

Más adelante, la Ley 1176 (2007), a través del Acto legislativo 04 (2007), modificó las reglas de participación porcentual y distribución del SGP ${ }^{14}$. Acorde con el acto, el monto total se incrementaría de 2008 a 2016 a tasas reales entre 3 y 4\% anual. Desde 2017, el aumento del SGP sería el promedio de la variación porcentual de los ingresos corrientes de la Nación durante los 4 años previos (Hernández y Barreto, 2018).

\footnotetext{
${ }^{10}$ Determinó la participación mínima municipal en los ingresos corrientes del gobierno central.

${ }^{11}$ En este rubro está agua potable, libre destinación, deporte, cultura y libre inversión.

${ }^{12}$ Los porcentajes indicados corresponden al promedio que tuvieron las asignaciones de las transferencias entre 1994 a 2001 (Hernández y Barreto, 2018).

${ }^{13}$ Reglamentado por la Ley 715 (2001).

${ }^{14}$ La distribución de las transferencias quedó definida para la asignación sectorial (96\%): educación (56.2\%), salud (23.5\%), propósito general (11.1\%), agua potable (5.2\%). En cambio, para la asignación especial (4\%) quedó: alimentación escolar (0.5\%), municipios ribereños del Río Grande de la Magdalena (0.1\%), resguardos indígenas (0.5\%) y FONPET (2.9\%).
} 
Otra fuente de financiación para los territorios son las regalías, reguladas por el Sistema General de Regalías (SGR), que tiene sustento normativo en algunos artículos de la CP (1991). Por ejemplo, el artículo 332 (CP, 1991) estableció que el subsuelo y los recursos naturales son propiedad del Estado. Igualmente, definió el canon ${ }^{15}$ de las regalías, así como el reparto, su uso y beneficiarios. Además, el artículo 360 y el artículo 361 (CP, 1991) especificaron que en los departamentos y municipios donde se hiciere explotación de recursos naturales no renovables, junto con los puertos marítimos-fluviales en los que se transportaran estos recursos o productos derivados, adquirirían el derecho a participar en las regalías y/o compensaciones.

También, se previó que los ingresos de las regalías que no se asignaran a los departamentos y municipios irían a un Fondo Nacional de Regalías cuyo destino definió el artículo 361 (CP, 1991) así: "se aplicarían a la promoción de la minería, a la preservación del ambiente y a financiar proyectos regionales de inversión definidos como prioritarios en los planes de desarrollo de las respectivas entidades territoriales".

Con el paso del tiempo, se evidenciaron algunas debilidades del SGP y del SGR. Respecto del SGP, Hernández y Barreto (2018) expresan que las transferencias territoriales han tenido un enfoque de arriba hacia abajo, que resta autonomía a los territorios porque el gobierno central, a través del Congreso de la República, establece reformas, porcentajes de asignación y define los tributos territoriales ${ }^{16}$.

Las debilidades del SGR provocaron que en 2010 se propusiera una reforma constitucional que pedía que las regalías no solo se distribuyeran entre los territorios donde se diera la explotación de los recursos, ya que había evidencia de corrupción en la ejecución de recursos. Hernández y Barreto (2018) indican que:

[...] entre 1999 y 2009 los departamentos y municipios minero energéticos recibieron el $87,2 \%$ de las regalías, mientras que el resto del país sólo recibió el 12,8\%. Por el contrario, el presupuesto del bienio 2015-2016 distribuyó a los territorios minero energéticos el 43,9\% (...) mientras que al resto del territorio nacional le correspondió el 56,1\% (p. 33).

En síntesis, la normativa alrededor de la descentralización se ha orientado a expedir leyes dirigidas a controlar los niveles de endeudamiento, sanear las finanzas locales y dar una mayor responsabilidad fiscal a los territorios, con el fin de ganar eficiencia en la asignación del gasto descentralizado y así reducir las disparidades existentes en materia de ingresos fiscales (Iregui, Ramos y Saavedra, 2001).

Sin embargo, para autores como Martínez (2006), Bonet y Meisel (2007) y Betancurt (2002), la descentralización no ha cumplido el propósito de reducir la desigualdad de los ingresos fiscales (generando significativas brechas entre territorios), lo cual se ha agravado por las transferencias del orden nacional, a través del SGP.

Además, de los niveles de desigualdad fiscal también se han visto disparidades en materia de educación, mortalidad infantil, cobertura en servicios públicos (Hernández y Barreto, 2018). Lo anterior se generó, según Betancurt (2002), porque se dejó de lado la equidad, que defendía la Ley 60 (1993), para priorizar la eficiencia.

\footnotetext{
${ }^{15}$ Según Hernández y Barreto (2018) "es un precio que pagan al Estado las compañías minero energéticas, neto de los costos ambientales de los proyectos" (p. 28).

${ }^{16} \mathrm{El}$ artículo $4^{\circ}$ de la Ley 44 (1990) le dio autonomía a los Concejos municipales para definir "la tarifa del impuesto predial entre el 1 y el 16 por mil. Autonomía parcial que se preservó en el artículo 23 de la Ley 1450 de 2011 que estableció que a discreción de los Concejos Municipales ese impuesto podría fluctuar entre el 5 y 16 por mil del avalúo catastral del predio" (Hernández y Barreto, 2018, p. 31)
} 
De ahí que es necesario que se dé mayor autonomía a los territorios para que puedan ir más allá del mero suministro de bienes básicos para la subsistencia y puedan asignar los recursos a otras necesidades tales como culturales, ecológicas, entre otras. Y, de este modo, invertir el enfoque habitual de la descentralización que suele ir de arriba hacia abajo, para garantizar un desarrollo local sostenible (Hernández y Barreto, 2018).

Por ende, la desigualdad de los ingresos fiscales es una de las cuestiones que ha generado mayores controversias de la descentralización. De ahí que este documento revisa el comportamiento de los ingresos fiscales de los municipios de Santander con el fin de establecer si se redujeron o no las disparidades entre los territorios del departamento. Esto se analiza en el resto de las secciones.

\section{Metodología}

Para revisar la dinámica de la desigualdad de los ingresos fiscales de los municipios de Santander, se usó la información de las ejecuciones presupuestales que los municipios reportan al Departamento Nacional de Planeación (DNP), desde 1985 a 2017. Con los datos de las ejecuciones, se calculó el grado de desigualdad fiscal, a través del índice de y el coeficiente de, con el propósito de confrontar si la descentralización logró reducir la desigualdad entre provincias (interprovincial) y dentro de los municipios de cada provincia (intraprovincial).

Sin embargo, al mencionar la igualdad, es necesario precisar, como lo hace Sen (1979): Igualdad ¿de qué? Esto es, hay varias aristas de esta, tales como igualdad de ingresos, de oportunidades, entre otras. No obstante, este documento se concentra en determinar si la desigualdad de los ingresos fiscales de los municipios de Santander aumentó o disminuyó durante el periodo señalado. En aras de hacer una comparación en los mismos términos se deflactaron los ingresos fiscales a precios de 2015. Luego se expresaron como indicadores per cápita para determinar, por un lado, cuánto le correspondería en promedio a cada persona y, por el otro, para visualizar el comportamiento de los municipios de Santander en términos de igualdad a través del tiempo (Guerrero, 2014).

La estructura de los ingresos fiscales se ilustra en la Figura 1. Así, los ingresos totales se clasifican entre corrientes y de capital. Los primeros están compuestos por tributarios, no tributarios, y transferencias. Dentro de los tributarios, están los impuestos del predial, industria y comercio, sobretasa y otros. Los ingresos no tributarios son aquellos que se obtienen por la prestación de bienes y servicios. En cuanto a las transferencias, estas pueden provenir del nivel nacional o de otras fuentes.

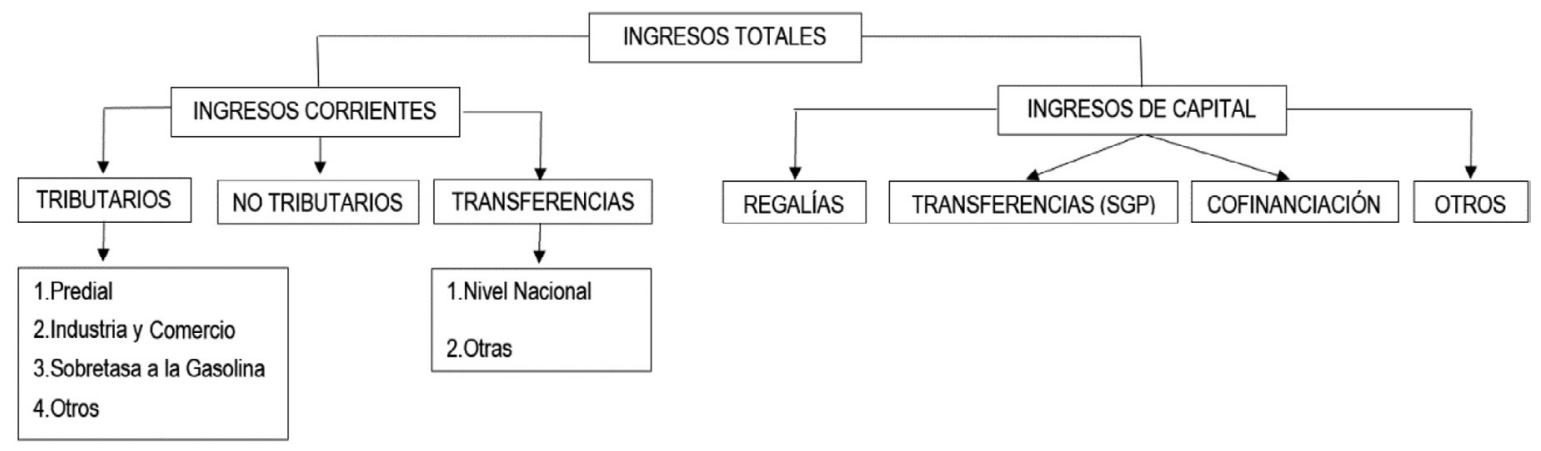

Figura 1. Sacrificios tributarios.

Fuente: Elaboración propia. 
Por otro lado, los ingresos de capital están conformados por regalías, transferencias, cofinanciación y otros. Básicamente, los ingresos de capital son aquellos recursos que provienen de regalías, venta de activos, así como los recursos que provienen por transferencias del gobierno nacional central, a través del Sistema General de Participaciones (SGP).

En ese sentido, este trabajo realizó el análisis sobre los siguientes ingresos: totales, corrientes, tributarios, no tributarios, predial e industria y comercio (ICA). Esto es, se basó en la siguiente hipótesis: la desigualdad de los ingresos fiscales de los municipios del departamento de Santander, para el periodo comprendido entre 1985 a 2017, en el marco del proceso de la descentralización fiscal, se redujo (aumentó) vía transferencias del gobierno nacional central o por el esfuerzo fiscal realizado por los municipios.

Para verificar la hipótesis se esperaría, a priori, que si la desigualdad disminuyó (aumentó) de los ingresos totales y se observa que la de los ingresos corrientes aumentó, entonces se deduce que el descenso(aumento) se dio vía transferencias del gobierno nacional central. En cambio, si sucede lo contrario se podría inferir que se debió al esfuerzo fiscal realizado por los municipios.

Es preciso indicar que se eligieron los ingresos fiscales, debido a que tanto las estructuras tributarias como las productivas, están estrechamente vinculadas. Igualmente, se cuenta con la implicación de que los impuestos del predial y el ICA, de algún modo reflejan la riqueza, el nivel de actividad y desarrollo económico de un municipio (Sánchez \& Núñez, 2000).

Así que, si se acepta, por un lado, tomar los ingresos fiscales señalados como variables proxy de los ingresos municipales y, por el otro, que los ingresos per cápita sirven para calcular las desigualdades entre los municipios de Santander. Entonces, se podría manifestar que el ejercicio de calcular el índice de Theil y el coeficiente de Gini de los ingresos fiscales permite determinar si el grado de desigualdad aumentó o disminuyó.

\section{Theil}

El índice de Theil, a diferencia del coeficiente de Gini, permite calcular la parte de la desigualdad que cada uno de los diferentes subgrupos (municipios) de análisis genera frente a la desigualdad total. El índice está restringido entre cero a uno. Si la variable está distribuida igualitariamente el índice tomará el valor de cero; en cambio, habrá desigualdad total si el valor es de uno. La ecuación 1 permite calcular el índice de Theil:

$$
T=\sum_{i=1}^{n} x_{i} \ln \left(x_{i} n\right)
$$

Donde $\mathrm{n}$ es el número de municipios, son los ingresos respectivos de cada municipio, es la participación porcentual del ingreso de cada municipio dentro del total de la variable (Lora, 2008). Cabe aclarar que, si para alguna de las observaciones no se cuenta con dato, no se tiene en cuenta en el cálculo.

Para calcular las desigualdades intra e inter provincias, se usó (2):

$$
T=T_{1}+T_{2}
$$


Siendo (3):

$$
\begin{aligned}
& T_{1}=\sum_{j} v_{j} \sum_{j} z_{i j} \ln \left(z_{i j} n_{j}\right) \\
& T_{2}=\sum_{j} v_{j} \ln \left(\frac{v_{j} n}{n_{j}}\right)
\end{aligned}
$$

Donde $V_{j}$ es la participación del grupo $j$ en el ingreso total, $Z_{i j}$ es la participación del municipio $i$ en el ingreso del grupo (provincia) $j$, es el número de municipios del grupo $j$, n es el número total de individuos. Además, $T_{1}$ (interprovincial) mide la contribución de la desigualdad dentro de los municipios que conforman la provincia; $T_{2}$ (intraprovincial) explica la contribución de cada provincia a la desigualdad total del departamento (Lora, 2008).

Valga decir que, cuando la distribución de los datos es dispersa se podría presentar que el índice de Theil, se salga del rango 0 a 1. Guerrero (2014), citando a Bacallao (2007), dice que el índice puede transformarse para que tome valores entre 0 a 1 , por medio de (4):

$$
Z_{T}=1-e^{-T}
$$

Donde $e$ es el número de Euler, $T$ es el Theil obtenido que requiere transformación, y es el valor de transformado. En consecuencia, se usó (4) cuando el índice se salió del rango señalado.

\section{Gini}

El coeficiente de Gini mide la superficie entre la curva de Lorenz y una línea hipotética de igualdad absoluta, expresada como porcentaje de la superficie máxima debajo de la línea. El coeficiente va de 0 y 1, donde 0 indica perfecta igualdad y 1 perfecta desigualdad (Lora, 2008). El coeficiente de Gini se calculó con (5):

$$
G=1-\sum_{i}\left(Y_{i-1}+Y_{i}\right)\left(N_{i}+N_{i-1}\right)
$$

Donde $Y_{i}$ y $N_{i}$ son porcentajes acumulados de ingreso y perceptores, respectivamente. A partir de estas precisiones metodológicas se procede a analizar los resultados obtenidos del cálculo del índice de Theil y el coeficiente de Gini y, de este modo, determinar si se redujo o no la desigualdad entre los municipios del departamento de Santander para el periodo 1985 a 2017.

\section{Resultados y AnÁLisis}

Los resultados de la tabla 1 muestran que la tendencia del Theil y el Gini es decreciente para todos los ingresos fiscales. Sin embargo, la mayor reducción se presentó 
en los ingresos totales y corrientes, en los otros la disminución es menor (última fila de la Tabla 1). Esto es relevante porque la desigualdad descendió, principalmente, por los ingresos que provienen de afuera de las dinámicas propias de los municipios, tales como: regalías, transferencias, cofinanciación y otros.

TABla 1.

Theil y Gini de los ingresos fiscales de los municipios de Santander (1985-2017).

\begin{tabular}{|c|c|c|c|c|c|c|c|c|c|c|c|c|}
\hline \multirow{2}{*}{ Año } & \multicolumn{2}{|c|}{ Totales } & \multicolumn{2}{|c|}{ Corrientes } & \multicolumn{2}{|c|}{ Tributarios } & \multicolumn{2}{|c|}{ Predial } & \multicolumn{2}{|c|}{ ICA } & \multicolumn{2}{|c|}{ No tributarios } \\
\hline & heil & Gini & Theil & Gini & Theil & Gini & Theil & Gini & heil & Gini & Theil & Gini \\
\hline & 307 & .339 & 0.307 & 339 & 0.333 & 0.422 & 0.253 & 379 & 0.738 & & .305 & .428 \\
\hline & 40 & & 340 & & & & 29 & & 816 & & .294 & 24 \\
\hline & 321 & 8 & 320 & 37 & 48 & 20 & 183 & & 758 & & 299 & \\
\hline & 24 & & 0.124 & & 338 & & 189 & & 806 & & 0.390 & 474 \\
\hline & & & 0.132 & & 0 & & & & & & & \\
\hline & 66 & 2 & 106 & & 02 & & 0.220 & & 838 & & 399 & 182 \\
\hline & 84 & & 0.084 & & 0 & & & & & & & \\
\hline & 60 & 0.171 & 0.060 & 71 & 0.356 & 423 & 0.199 & & .841 & 16 & .343 & 454 \\
\hline & 50 & 155 & 0.049 & & 0.453 & 50 & 0.197 & & 0.888 & 47 & 0.366 & 428 \\
\hline & 18 & 0.191 & .114 & 0 & 0.441 & 455 & 0.192 & & 0.865 & & 0.391 & 472 \\
\hline & 68 & 9 & .068 & & 0.341 & & 0.202 & & 826 & & 0.439 & 06 \\
\hline & 13 & 0.318 & 0.230 & & 0.602 & & 0.393 & & 0.869 & & 0.841 & 666 \\
\hline & & & 496 & & 79 & & 70 & & 837 & & 2 & \\
\hline 195 & 91 & 0. & 0.203 & & 0.541 & & 26 & & 0.852 & & 1 & 99 \\
\hline & & 0.296 & 238 & - & 0.721 & 06 & 0.300 & & 882 & & 44 & 09 \\
\hline & 89 & 0.317 & .212 & 0.327 & 0.583 & 33 & 0.264 & & 0.885 & 67 & 7 & 24 \\
\hline & & & $1+$ & & & & 0.246 & & 86 & & 21 & 91 \\
\hline 02 & 09 & 8 & 139 & 0.286 & 423 & 179 & 0.233 & & 852 & 22 & 0.525 & 552 \\
\hline & & & 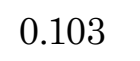 & & 0. & & 0.205 & & & & & \\
\hline & 02 & 0 & .115 & 0 & 0.310 & 03 & 0.202 & & 798 & & 24 & 40 \\
\hline 2005 & 99 & 0 & 0.116 & 4 & 0.307 & 87 & 0.147 & & 0.837 & & 0.359 & 0.448 \\
\hline & 99 & 0 & 0.106 & 51 & 0.298 & 0.394 & 0.220 & & 0.805 & & 8 & 0.433 \\
\hline & 21 & 0 & 138 & 1 & .337 & 15 & 0.250 & & 0.815 & & 5 & 0.413 \\
\hline & & & & & & & & & & & 00 & 0.429 \\
\hline 2009 & 888 & 0 & 0.119 & 32 & 0.293 & 88 & 0.216 & 0 & 0.757 & 15 & 14 & 481 \\
\hline & & & & & & & 0.203 & & & & & \\
\hline 2011 & .00 & 0.2 & 0.136 & 0. & 0.256 & 0.360 & 0.182 & 0.000 & 0.761 & 0.738 & 0.275 & 0.410 \\
\hline & & & 0.151 & & & & & & 0.793 & & 0.297 & \\
\hline or & 70 & 0 & 0.119 & & 0.267 & 34 & 0.189 & & 0.733 & 27 & 0.295 & 20 \\
\hline 2014 & 081 & 0.226 & 0.110 & 0.256 & 0.220 & 0.331 & 0.216 & 0.357 & 0.672 & 0.680 & 0.300 & 0.422 \\
\hline & & & 0.114 & & & & 0.280 & & 0.612 & & 0.273 & 0.403 \\
\hline 2016 & .084 & 0.227 & 0.103 & 0.245 & 0.200 & 0.332 & 0.228 & & 0.572 & 0.617 & 0.244 & 0.384 \\
\hline & & & & & & & & & 0.563 & & 0.220 & 0.364 \\
\hline & 111 & . & .157 & 0 & 0.385 & 0424 & ro 0 & 0. & 0.798 & 0 & 0.413 & 0478 \\
\hline 01 & .20 & -0.0 & -0.20 & -0.09 & -0.12 & -0.08 & -0.02 & -0 & -0.17 & -0.15 & -0.08 & -0.06 \\
\hline
\end{tabular}

Fuente: Cálculos propios en Stata 12, con base en las ejecuciones presupuestales del DNP. 
El Theil de los ingresos totales per cápita fluctuó entre 0.43 y 0.05 ; en cambio, el Gini varió entre 0.45 y 0.15 . En cuanto a los ingresos corrientes el Theil alcanzó su máximo (0.49) en 1997 y su mínimo (0.04) en 1993; para el Gini se tuvo un máximo de 0.48 y un mínimo de 0.15 en los mismos años.

Por el lado de los ingresos que dependen, en mayor medida, del esfuerzo fiscal de los municipios, se tuvo un máximo para el Theil y el Gini de los ingresos tributarios per cápita de 0.77 y 0.64 en 1993 y un mínimo de 0.18 y 0.31 en 2015, respectivamente. Por el lado del predial, el Theil fluctuó entre 0.57 y 0.14; en cambio, el Gini varió entre 0.55 y 0.3. En el ICA, se tuvieron los peores índices, ya que el Theil tuvo su máximo en 1993 con un valor de 0.888 y un mínimo de 0.563 en 2017; en cambio, el Gini alcanzó su máximo en 1999 con un valor de 0.87 y el mínimo en 2017 con un 0.59. Por último, los ingresos no tributarios tuvieron un máximo para el Theil y el Gini de 0.89 y 0.67 en 1997, y un mínimo de 0.22 y 0.36 en 2017 , respectivamente.

En todo caso, se observa que a lo largo del periodo de análisis el Theil (Figura 2) y el Gini (Figura 3) para las seis variables tuvieron un comportamiento irregular de tipo ascensor. De hecho, en las figuras se aprecia que el comportamiento alcanzó sus máximos en el lapso comprendido entre 1995 a 1999, en el que la actividad económica de Colombia se resintió.

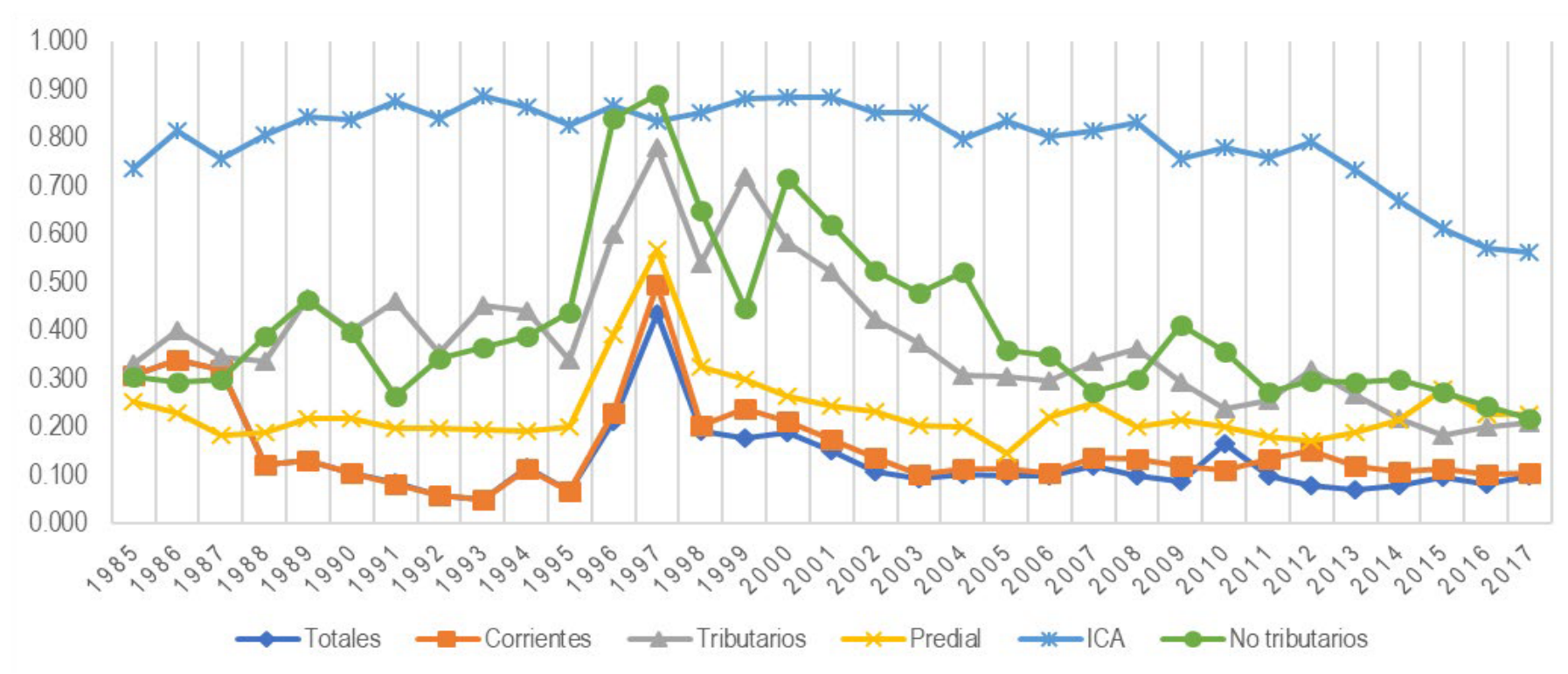

Figura 2. Theil de los ingresos fiscales de los municipios de Santander (1985-2017). Fuente: Construcción propia a partir de las ejecuciones presupuestales del DNP.

De acuerdo con Garay (2004), entre 1990-1995, se presentó un significativo crecimiento de la demanda doméstica que se detuvo, desde finales de 1995. Lo anterior, sucedió cuando la economía experimentó un estancamiento, producto de las altas tasas de interés, la desaceleración de la construcción, la revaluación del peso y la elevada inflación. Además, para 1999 el aumento del déficit en balanza de pagos, junto con un desempleo del 20\% y una devaluación real puso en evidencia la debilidad de la economía del país. La acumulación de estos factores llevó a experimentar la peor crisis económica de Colombia. 


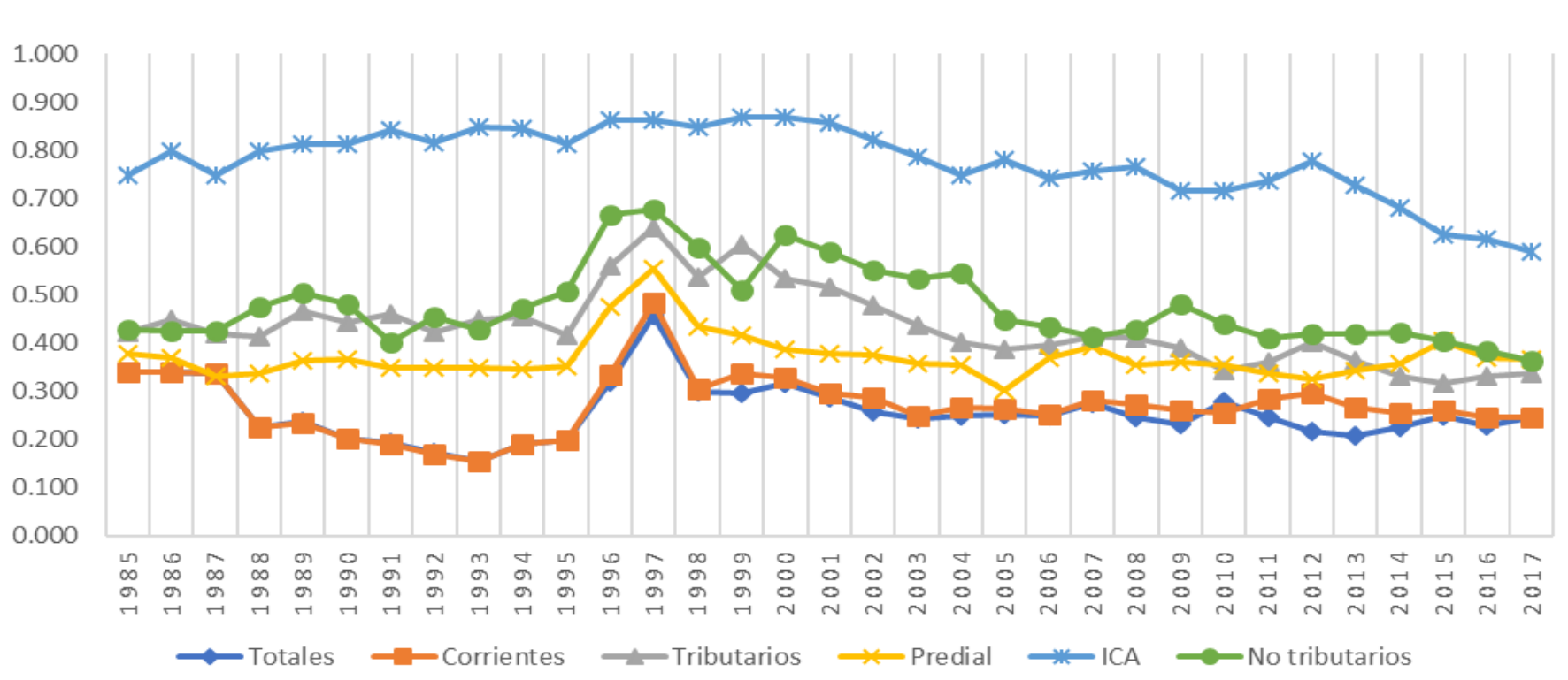

Figura 3. Gini de los ingresos fiscales de los municipios de Santander (1985-2017).

Fuente: Construcción propia a partir de las ejecuciones presupuestales publicadas por el DNP.

A comienzos del siglo XXI, se generó un descenso de ambos índices. En la Tabla 2 se destacan dos hechos. Por un lado, el Theil y el Gini de los ingresos per cápita totales y corrientes en los periodos 1985-1999 y 1999-2017 se redujeron. Pero, por el otro lado, el Theil y el Gini de los ingresos propios de los municipios experimentó dos tendencias opuestas: aumento en el primer periodo y descenso en el segundo.

TABLA 2.

Variación Theil y Gini de los ingresos fiscales de los municipios de Santander entre 1985 a 1999 y 1999 a 2017.

\begin{tabular}{ccccccccccccccc}
\hline \multirow{2}{*}{ Periodo } & \multicolumn{3}{c}{ Totales } & \multicolumn{3}{c}{ Corrientes } & \multicolumn{2}{c}{ Tributarios } & \multicolumn{2}{c}{ Predial } & \multicolumn{3}{c}{ ICA } & \multicolumn{3}{c}{ No tributarios } \\
\cline { 2 - 14 } & Theil & Gini & Theil & Gini & Theil & Gini & Theil & Gini & Theil & Gini & Theil & Gini \\
\hline$\Delta 1999-1985$ & -0.13 & -0.04 & -0.07 & 0.00 & 0.39 & 0.18 & 0.05 & 0.04 & 0.14 & 0.12 & 0.14 & 0.08 \\
$\Delta 2017-1999$ & -0.08 & -0.05 & -0.13 & -0.09 & -0.51 & -0.27 & -0.07 & -0.05 & -0.32 & -0.28 & -0.23 & -0.14 \\
\hline
\end{tabular}

Fuente: Cálculos propios en Stata 12, con base en las ejecuciones presupuestales del DNP.

Así, para el periodo 1985-1999, la desigualdad aumentó; mientras que para el periodo 1999-2017 se redujo. De lo anterior, se infiere que las transferencias contribuyeron a la reducción de la desigualdad para los ingresos totales y corrientes, no así para los ingresos gestionados por las propias administraciones municipales (tributarios, no tributarios, ICA y predial).

\section{Theil interprovincial e intraprovincial}

Para comprender la procedencia de las disparidades de los municipios de Santander, se calculó el Theil interprovincial (dentro de los municipios que componen las provincias) e intraprovincial (dentro de las provincias del departamento). Al usar (5), se obtuvieron los resultados de la Tabla 3. 
TABLA 3.

Theil interprovincial e intraprovincial de los ingresos fiscales de los municipios de Santander (1985-2017).

\begin{tabular}{|c|c|c|c|c|c|c|c|c|c|c|c|c|}
\hline \multirow{2}{*}{ Año } & \multicolumn{2}{|c|}{ Totales } & \multicolumn{2}{|c|}{ Corrientes } & \multicolumn{2}{|c|}{ Tributarios } & \multicolumn{2}{|c|}{ Predial } & \multicolumn{2}{|c|}{ ICA } & \multicolumn{2}{|c|}{ No tributarios } \\
\hline & Inter & Intra & Inter & Intra & Inter & Intra & Inter & Intra & Inter & Intra & Inter & Intra \\
\hline 85 & 0.24 & 0.07 & 0.24 & 0.07 & 0.29 & 0.05 & 0.22 & 0.03 & 0.57 & 0.17 & 0.27 & 0.03 \\
\hline 1986 & 0.26 & 0.08 & 0.26 & 0.08 & 0.34 & 0.06 & 0.20 & 0.03 & 0.55 & 0.26 & 0.26 & 0.03 \\
\hline 1987 & 0.25 & 0.07 & 0.25 & 0.07 & 0.30 & 0.05 & 0.16 & 0.02 & 0.54 & 0.22 & 0.27 & 0.03 \\
\hline 1988 & 0.10 & 0.03 & 0.10 & 0.03 & 0.27 & 0.06 & 0.16 & 0.03 & 0.57 & 0.23 & .36 & 0.03 \\
\hline 1989 & 0.10 & 0.03 & 0.10 & 0.04 & 0.38 & 0.09 & 0.20 & 0.01 & 0.56 & 0.29 & 0.37 & 0.09 \\
\hline 1990 & 0.07 & 0.04 & 0.07 & 0.03 & 0.31 & 0.10 & 0.18 & 0.04 & 0.52 & 0.32 & 0.35 & 0.05 \\
\hline 1991 & 0.07 & 0.02 & 0.07 & 0.02 & 0.35 & 0.11 & 0.16 & 0.04 & 0.51 & 0.36 & 0.24 & 0.02 \\
\hline 1992 & 0.05 & 0.01 & 0.05 & 0.01 & 0.29 & 0.07 & 0.17 & 0.03 & 0.52 & 0.32 & 0.33 & 0.01 \\
\hline 1993 & 0.04 & 0.01 & 0.04 & 0.01 & 0.34 & 0.11 & 0.16 & 0.04 & 0.52 & 0.36 & 0.30 & 0.07 \\
\hline 1994 & 0.11 & 0.01 & 0.10 & 0.01 & 0.34 & 0.10 & 0.16 & 0.03 & 0.51 & 0.35 & 0.30 & 0.09 \\
\hline 1995 & 0.06 & 0.01 & 0.07 & 0.00 & 0.26 & 0.08 & 0.15 & 0.05 & 0.52 & 0.31 & 0.38 & 0.06 \\
\hline 1996 & 0.20 & 0.01 & 0.22 & 0.01 & 0.49 & 0.11 & 0.32 & 0.07 & 0.55 & 0.32 & 0.72 & 0.12 \\
\hline 1997 & 0.41 & 0.02 & 0.46 & 0.04 & 0.67 & 0.11 & 0.45 & 0.12 & 0.59 & 0.25 & 0.82 & 0.07 \\
\hline 1998 & 0.18 & 0.01 & 0.19 & 0.01 & 0.45 & 0.09 & 0.30 & 0.03 & 0.56 & 0.30 & 0.53 & 0.12 \\
\hline 1999 & 0.16 & 0.01 & 0.22 & 0.02 & 0.57 & 011 & 0.26 & 0.04 & 0.56 & 0.32 & 0.43 & 0.01 \\
\hline 2000 & 0.17 & 0.02 & 0.18 & 0.04 & 0.47 & 0.12 & 0.23 & 0.03 & 0.54 & 0.35 & 0.54 & 0.18 \\
\hline 2001 & 0.13 & 0.02 & 0.16 & 0.01 & 0.46 & 0.06 & 0.22 & 0.02 & 0.57 & 0.31 & 0.46 & 0.16 \\
\hline 2002 & 0.09 & 0.02 & 0.13 & 0.01 & 0.39 & 0.03 & 0.20 & 0.03 & 0.61 & 0.25 & 0.44 & 0.08 \\
\hline 2003 & 0.08 & 0.01 & 0.10 & 0.00 & 0.32 & 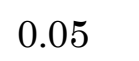 & 0.18 & 0.02 & .10 & 0.00 & 0.47 & \\
\hline 2004 & 0.09 & 0.01 & 0.11 & 0.01 & 0.26 & 0.05 & 0.18 & 0.02 & 0.43 & 0.37 & 0.47 & 0.06 \\
\hline 2005 & 0.09 & 0.01 & 0.10 & 0.01 & 0.25 & 0.06 & 0.13 & 0.02 & 0.48 & 0.35 & 0.31 & 0.05 \\
\hline 2006 & 0.09 & 0.00 & 0.10 & 0.01 & 0.24 & 0.06 & 0.20 & 0.02 & 0.45 & 0.36 & 0.29 & 0.06 \\
\hline 2007 & 0.11 & 0.01 & 0.12 & 0.02 & 0.28 & 0.06 & 0.22 & 0.03 & 0.40 & 0.36 & 0.23 & 0.04 \\
\hline 2008 & 0.09 & 0.01 & 0.12 & 0.01 & 0.27 & 0.10 & 0.17 & 0.03 & 0.44 & 0.39 & 0.24 & 0.06 \\
\hline 2009 & 0.08 & 0.01 & 0.11 & 0.01 & 0.22 & 0.07 & 0.18 & 0.04 & 0.40 & 0.36 & 0.36 & 0.05 \\
\hline 2010 & 0.16 & 0.01 & 0.10 & 0.01 & 0.18 & 0.06 & 0.17 & 0.03 & 0.41 & 0.37 & 0.32 & 0.04 \\
\hline 2011 & 0.09 & 0.01 & 0.12 & 0.01 & 0.17 & 0.08 & 0.16 & 0.03 & 0.34 & 0.42 & 0.23 & 0.05 \\
\hline 2012 & 0.08 & 0.00 & 0.14 & 0.01 & 0.24 & 0.08 & 0.15 & 0.02 & 0.40 & 0.39 & 0.25 & 0.04 \\
\hline 2013 & 0.07 & 0.00 & 0.11 & 0.01 & 0.18 & 0.09 & 0.16 & 0.03 & 0.35 & 0.38 & 0.25 & 0.05 \\
\hline 2014 & 0.07 & 0.01 & 0.10 & 0.01 & 0.15 & 0.07 & 0.17 & 0.04 & 0.34 & 0.33 & 0.26 & 0.04 \\
\hline 2015 & 0.08 & 0.01 & 0.11 & 0.00 & 0.15 & 0.03 & 0.22 & 0.06 & 0.30 & 0.31 & 0.24 & 0.04 \\
\hline 2016 & 0.08 & 0.01 & 0.10 & 0.00 & 0.16 & 0.04 & 0.18 & 0.05 & 0.35 & 0.22 & 0.22 & 0.02 \\
\hline 2017 & 0.09 & 0.01 & 0.10 & 0.00 & 0.17 & 0.04 & 0.17 & 0.06 & 0.34 & 0.22 & 0.19 & 0.03 \\
\hline $\begin{array}{l}\Delta 2017- \\
1985\end{array}$ & .15 & 0.06 & -0.14 & -0.06 & -0.12 & -0.01 & -0.05 & 0.02 & -0.23 & 0.05 & -0.09 & 0.00 \\
\hline Media & 0.122 & 0.019 & 0.138 & 0.019 & 0.310 & 0.075 & 0.198 & 0.037 & 0.480 & 0.318 & 0.355 & 0.057 \\
\hline
\end{tabular}

Fuente: Cálculos propios en Excel, con base en las ejecuciones presupuestales del DNP. 
En la penúltima fila de la Tabla 3, se muestra la diferencia que experimentó tanto el Theil interprovincial como intraprovincial entre 2017 a 1985. En esta, se ve que los seis resultados del Theil interprovincial (Figura 4) se redujeron, o sea que la desigualdad al interior de los municipios, a lo largo del periodo, disminuyó.

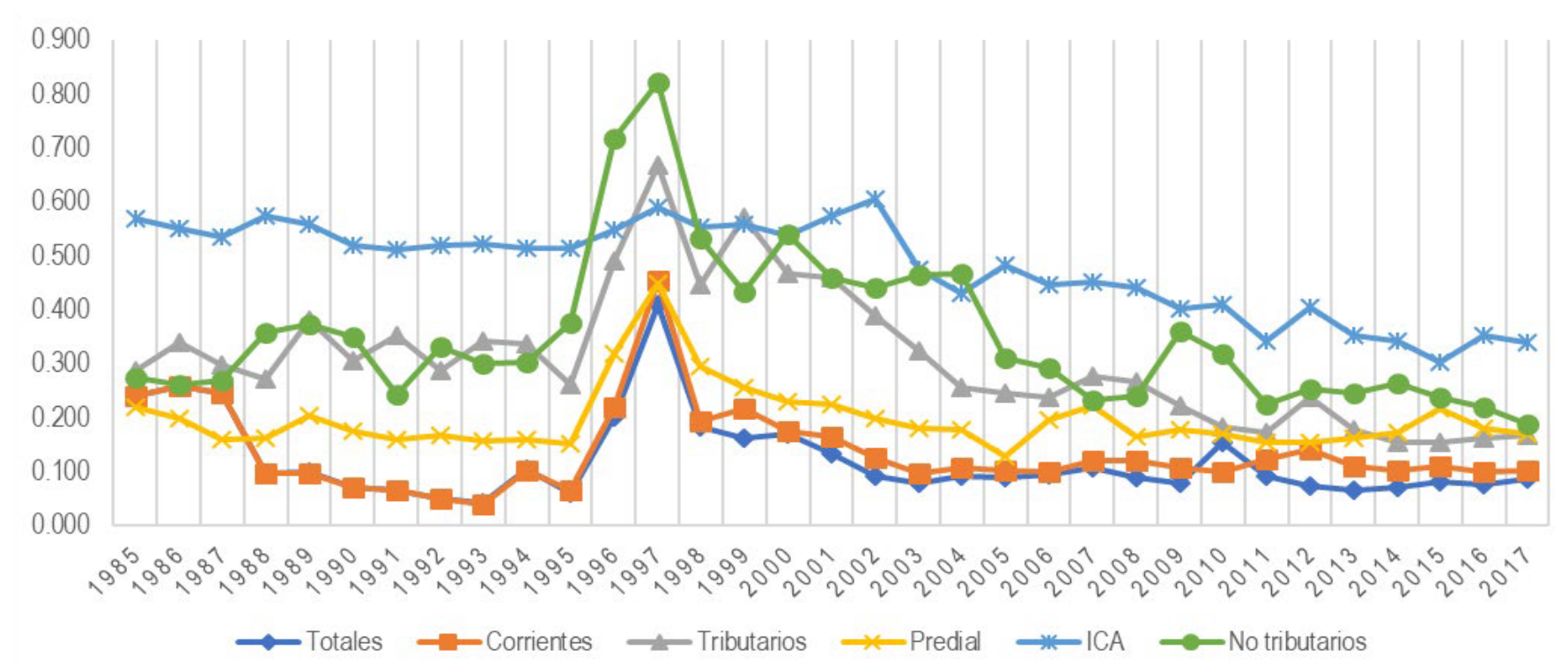

Figura 4. Theil interprovincial de los ingresos fiscales de los municipios de Santander (1985-2017).

Fuente: Construcción propia a partir de las ejecuciones presupuestales publicadas por el DNP.

En cambio, los Theil intraprovinciales (Figura 5) del predial y del ICA aumentaron, pasando de 0.03 y 0.17 en 1985 a 0.06 y 0.22 . Para el resto de los ingresos, hubo descensos, que oscilaron entre 0.06 a 0.01 , excepto para los no tributarios que se estancó en 0.03 .

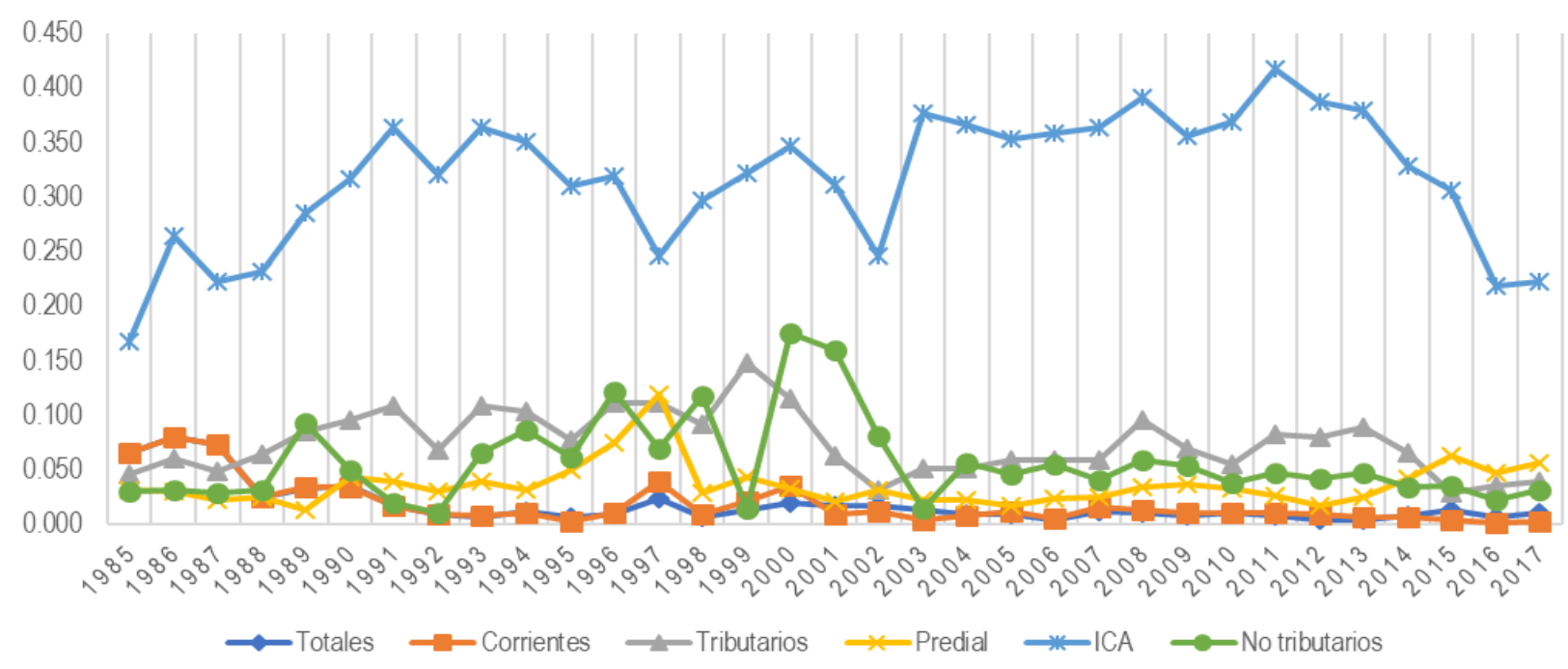

Figura 5. Theil intraprovincial de los ingresos fiscales de los municipios de Santander (1985-2017).

Fuente: Construcción propia a partir de las ejecuciones presupuestales publicadas por el DNP. 
Para comprender la procedencia de las desigualdades entre municipios y provincias del departamento, se hicieron dos ejercicios complementarios. El primero estableció los porcentajes promedio inter e intraprovincial de cada una de las seis provincias del departamento ${ }^{17}$. El segundo determinó las diferencias de ingresos entre los municipios, expresadas en el número de veces que representa cada ingreso en relación con el que aparece clasificado en primer lugar.

\section{Porcentajes promedio inter e intraprovincial}

Este ejercicio utilizó la ecuación 2, para descomponer el Theil de la penúltima fila de la Tabla 1 entre el Theil interprovincial e intraprovincial. A manera de explicación, si se toma el valor promedio del Theil de los ingresos no tributarios de 0.413 , se puede observar, en la última fila de la Tabla 3 , que 0.355 correspondió a la dinámica propia de los municipios de la provincia ( $T_{1}$ : interprovincial), mientras que 0.057 a la dinámica entre las provincias del departamento $\left(T_{2}\right.$ : intraprovincial).

Pero yendo a un análisis, basado en la aportación porcentual promedio a lo largo del periodo de análisis, se deduce a nivel interprovincial (Tabla 4) que el $86.6 \%$ de la desigualdad de los ingresos no tributarios per cápita se explicó por las dinámicas internas de los municipios de las provincias. En cambio, el $13.4 \%$ de la desigualdad se sustentó por la interacción entre las seis provincias del departamento.

TABLA 4.

Contribución porcentual media, de los municipios, a la desigualdad total de la provincia (1985-2017)

\begin{tabular}{lcccccccccccc}
\hline \multirow{2}{*}{ Provincia } & \multicolumn{2}{c}{ Totales } & \multicolumn{2}{c}{ Corrientes } & \multicolumn{2}{c}{ Tributarios } & \multicolumn{2}{c}{ Predial } & \multicolumn{2}{c}{ ICA } & \multicolumn{2}{c}{ No tributarios } \\
\cline { 2 - 13 } & Inter & Intra & Inter & Intra & Inter & Intra & Inter & Intra & Inter & Intra & Inter & Intra \\
\hline Soto & $21.0 \%$ & $79.0 \%$ & $28.5 \%$ & $71.5 \%$ & $80.1 \%$ & $19.9 \%$ & $56.7 \%$ & $43.3 \%$ & $82.1 \%$ & $17.9 \%$ & $28.0 \%$ & $72.0 \%$ \\
Mares & $66.2 \%$ & $33.8 \%$ & $64.4 \%$ & $35.6 \%$ & $45.0 \%$ & $55.0 \%$ & $89.7 \%$ & $10.3 \%$ & $41.5 \%$ & $58.5 \%$ & $144.8 \%$ & $-44.8 \%$ \\
Comunera & $45.1 \%$ & $54.9 \%$ & $33.9 \%$ & $66.1 \%$ & $86.8 \%$ & $13.2 \%$ & $38.8 \%$ & $61.2 \%$ & $-74.0 \%$ & $174.0 \%$ & $79.9 \%$ & $20.1 \%$ \\
García- & $31.2 \%$ & $68.8 \%$ & $-46 \%$ & $146 \%$ & $-29.1 \%$ & $129.1 \%$ & $88.6 \%$ & $11.4 \%$ & $-84.5 \%$ & $184.5 \%$ & $69.7 \%$ & $30.3 \%$ \\
Rovira & & & & & & & & & & & & \\
Guanentá & $16.0 \%$ & $84.0 \%$ & $34.3 \%$ & $65.7 \%$ & $137.6 \%$ & $-37.6 \%$ & $-269.9 \%$ & $369.9 \%$ & $-117.0 \%$ & $217.0 \%$ & $64.5 \%$ & $35.5 \%$ \\
Vélez & $-59 \%$ & $159 \%$ & $10.4 \%$ & $89.6 \%$ & $15.4 \%$ & $84.6 \%$ & $-178.9 \%$ & $278.9 \%$ & $-55.8 \%$ & $155.8 \%$ & $-582.3 \%$ & $682.3 \%$ \\
Total & $87.4 \%$ & $12.6 \%$ & $88.6 \%$ & $11.4 \%$ & $79.9 \%$ & $20.1 \%$ & $84.6 \%$ & $15.4 \%$ & $60.0 \%$ & $40.0 \%$ & $86.6 \%$ & $13.4 \%$ \\
\hline
\end{tabular}

Fuente: Cálculos propios en Excel, con base en las ejecuciones presupuestales del DNP.

${ }^{17}$ La Ordenanza No. 010 (2019) definió 7 provincias para el departamento. No obstante, para el periodo 1985-2017 había 6 provincias, por eso el documento hizo el análisis con las 6 . 
Si se desea hacer un análisis más puntual, con los ingresos no tributarios per cápita, se podría señalar que para la provincia de Mares pesó, en mayor medida, con un $144.8 \%$ la desigualdad entre sus municipios; y en menor medida, la de los municipios de la provincia de Vélez con un -582.3\%. Por otro lado, la desigualdad se incrementó para la provincia de Vélez por la dinámica intraprovincial, afectándola en un 682.3\%; mientras que para la de Mares la dinámica del resto de provincias del departamento contribuyó a que la desigualdad disminuyera en un $44.8 \%$.

Por otra parte, en la Tabla 5 se muestra el porcentaje promedio que cada provincia contribuyó al total de la desigualdad departamental de cada uno de los ingresos fiscales per cápita, a lo largo del periodo 1985-2017. Así que siguiendo con el análisis de los ingresos no tributarios se obtiene que la provincia que más contribuyó al incremento de la desigualdad de Santander fue la de Comunera (27.7\%), le siguieron Mares (20.5\%), Soto (18\%), Guanentá (14.7\%), Vélez (12.7\%) y García-Rovira (6.5\%).

TABLA 5.

Contribución porcentual media, por provincias, a la desigualdad total de Santander (1985-2017)

\begin{tabular}{lllllll}
\hline \multicolumn{1}{c}{ Provincia } & Totales & Corrientes & Tributarios & Predial & ICA & No tributarios \\
\hline Soto & $8.3 \%$ & $13.8 \%$ & $20.2 \%$ & $40.0 \%$ & $16.2 \%$ & $18.0 \%$ \\
Mares & $31.5 \%$ & $42.4 \%$ & $68.9 \%$ & $7.8 \%$ & $86.3 \%$ & $20.5 \%$ \\
Comunera & $17.8 \%$ & $16.3 \%$ & $1.8 \%$ & $35.7 \%$ & $-2.8 \%$ & $27.7 \%$ \\
García-Rovira & $10.7 \%$ & $-4.0 \%$ & $-8.9 \%$ & $-13.5 \%$ & $-1.2 \%$ & $6.5 \%$ \\
Guanentá & $31.5 \%$ & $25.5 \%$ & $5.0 \%$ & $22.3 \%$ & $-1.2 \%$ & $14.7 \%$ \\
Vélez & $0.2 \%$ & $6.0 \%$ & $13.0 \%$ & $7.8 \%$ & $2.7 \%$ & $12.7 \%$ \\
Total & $100 \%$ & $100 \%$ & $100 \%$ & $100 \%$ & $100 \%$ & $100 \%$ \\
\hline
\end{tabular}

Fuente: Cálculos propios en Excel, con base en las ejecuciones presupuestales del DNP.

De la Tabla 5 se deduce que la provincia de Mares contribuyó, en mayor medida, a la desigualdad de los ingresos fiscales per cápita del departamento. De hecho, el cálculo del promedio de los seis tipos de ingresos arrojó que Mares aportó a la desigualdad departamental un $42.9 \%$, seguida de las provincias de Soto con $19.42 \%$, Guanentá con $16.3 \%$, Comunera con 16.08\%, Vélez con 7.07\% y GarcíaRovira con $-1.73 \%$.

El caso de la provincia García-Rovira puede parecer un sinsentido. Sin embargo, podría estar indicando que hay una mejor distribución de los ingresos fiscales entre los habitantes de la provincia; es decir, las diferencias entre ingresos bajos o altos no son excesivas. Caso contrario se explicaría para el caso de los habitantes de la provincia de Mares. Con el fin de corroborar esta interpretación se procede a identificar las diferencias municipales de los ingresos fiscales per cápita. 


\section{Diferencias en los ingresos fiscales per cápita municipales}

Para obtener las diferencias de los ingresos fiscales per cápita entre los municipios de Santander, se obtuvo el promedio de cada uno de los municipios de los seis tipos de ingreso, a lo largo del periodo 1985-2017. En seguida, se organizó, de mayor a menor, el valor medio de cada uno de los ingresos para obtener el porcentaje que se distancia cada ingreso municipal frente al ingreso más alto (Tabla 6).

TABLA 6.

Diferencia porcentual de los ingresos fiscales per cápita, por municipio

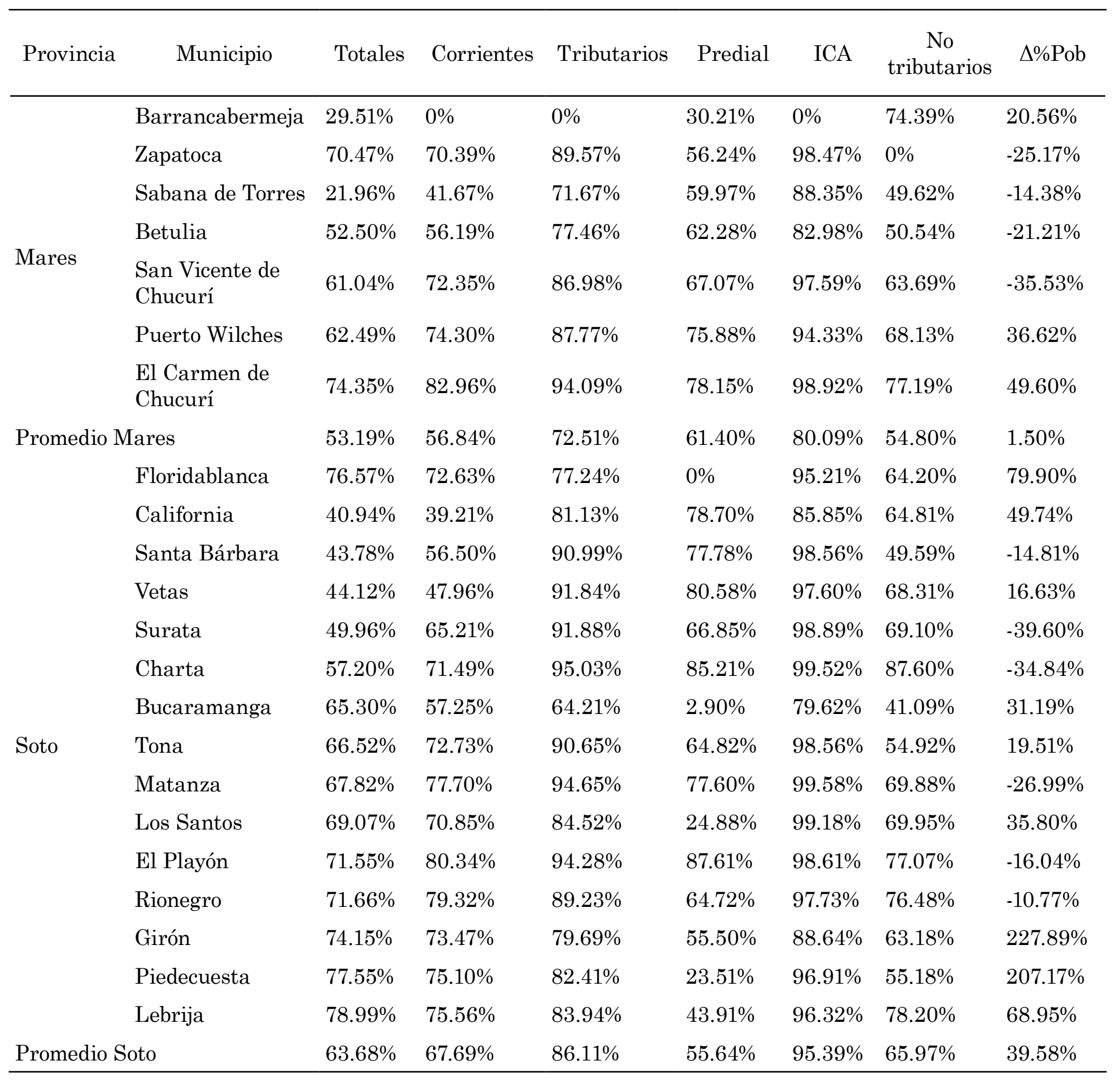




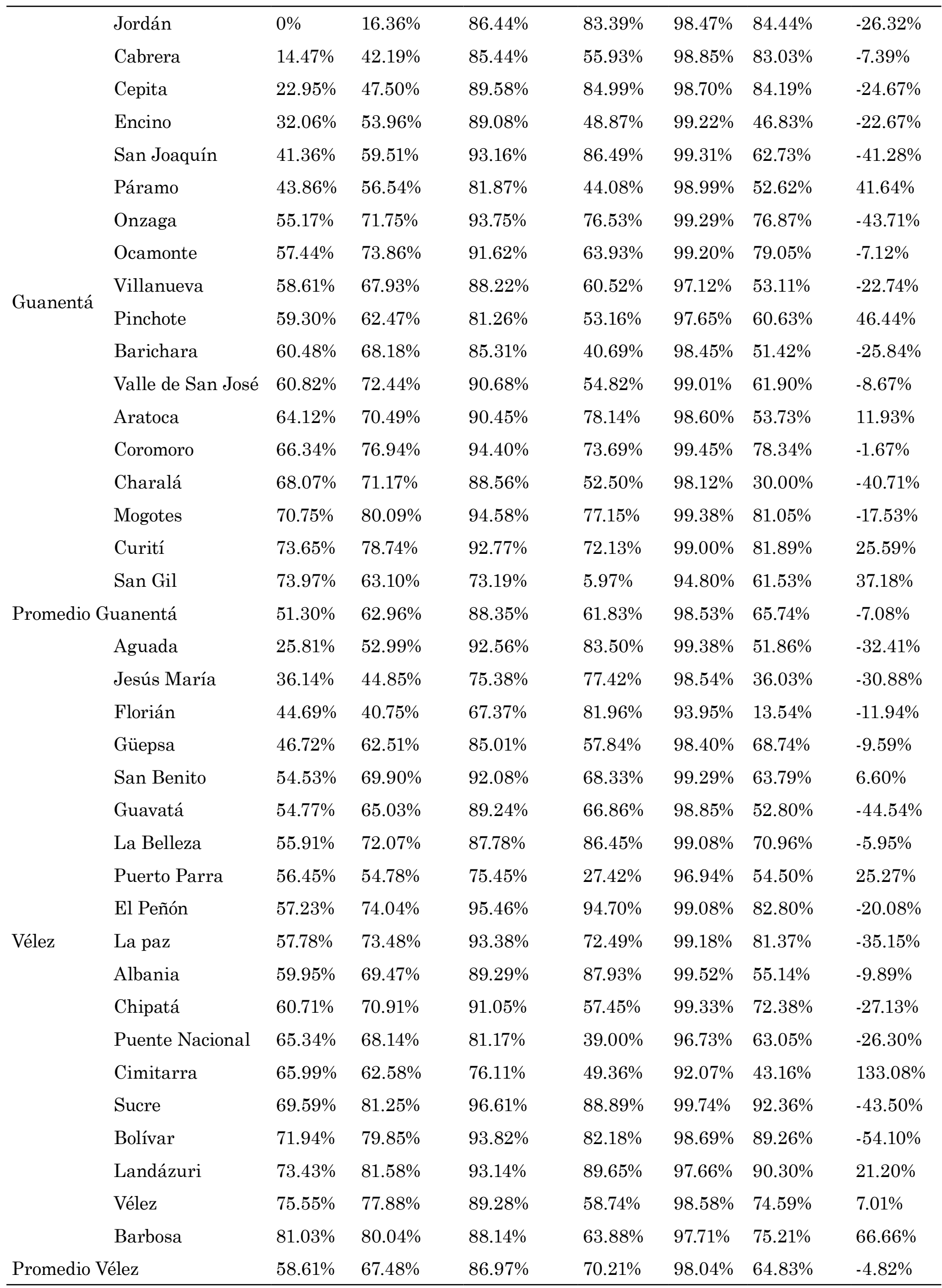




\begin{tabular}{|c|c|c|c|c|c|c|c|c|}
\hline & San Miguel & $27.10 \%$ & $51.22 \%$ & $91.83 \%$ & $84.64 \%$ & $99.90 \%$ & $74.11 \%$ & $-48.49 \%$ \\
\hline & Macaravita & $27.61 \%$ & $56.14 \%$ & $91.98 \%$ & $77.93 \%$ & $98.96 \%$ & $72.93 \%$ & $-51.03 \%$ \\
\hline & Enciso & $40.19 \%$ & $63.95 \%$ & $93.15 \%$ & $80.77 \%$ & $98.65 \%$ & $66.05 \%$ & $-37.28 \%$ \\
\hline & $\begin{array}{l}\text { San José de } \\
\text { Miranda }\end{array}$ & $51.91 \%$ & $66.66 \%$ & $91.01 \%$ & $84.10 \%$ & $97.41 \%$ & $73.17 \%$ & $-40.28 \%$ \\
\hline & Carcasí & $52.14 \%$ & $69.44 \%$ & $94.43 \%$ & $86.27 \%$ & $99.26 \%$ & $85.78 \%$ & $-34.78 \%$ \\
\hline García- & Concepción & $52.86 \%$ & $73.15 \%$ & $93.39 \%$ & $81.25 \%$ & $98.73 \%$ & $64.88 \%$ & $-34.13 \%$ \\
\hline & Capitanejo & $57.24 \%$ & $69.03 \%$ & $91.60 \%$ & $86.54 \%$ & $97.86 \%$ & $46.75 \%$ & $-31.79 \%$ \\
\hline & Cerrito & $57.78 \%$ & $71.17 \%$ & $92.33 \%$ & $84.75 \%$ & $98.38 \%$ & $73.83 \%$ & $-15.03 \%$ \\
\hline & Molagavita & $60.08 \%$ & $74.72 \%$ & $94.65 \%$ & $84.10 \%$ & $99.18 \%$ & $88.89 \%$ & $-40.74 \%$ \\
\hline & Guaca & $64.44 \%$ & $78.58 \%$ & $95.55 \%$ & $81.74 \%$ & $99.32 \%$ & $84.16 \%$ & $-25.61 \%$ \\
\hline & San Andrés & $64.61 \%$ & $74.58 \%$ & $93.52 \%$ & $74.51 \%$ & $99.30 \%$ & $39.41 \%$ & $-39.98 \%$ \\
\hline & Málaga & $73.94 \%$ & $76.29 \%$ & $87.86 \%$ & $60.48 \%$ & $97.06 \%$ & $71.69 \%$ & $9.22 \%$ \\
\hline Promedio $\mathrm{C}$ & Tarcía-Rovira & $52.49 \%$ & $68.74 \%$ & $92.61 \%$ & $80.59 \%$ & $98.67 \%$ & $70.14 \%$ & $-32.49 \%$ \\
\hline & El Guacamayo & $28.94 \%$ & $52.86 \%$ & $89.26 \%$ & $66.73 \%$ & $99.25 \%$ & $58.54 \%$ & $-43.02 \%$ \\
\hline & Hato & $29.65 \%$ & $47.65 \%$ & $90.95 \%$ & $65.11 \%$ & $99.33 \%$ & $19.89 \%$ & $-8.08 \%$ \\
\hline & $\begin{array}{l}\text { Palmas del } \\
\text { Socorro }\end{array}$ & $36.85 \%$ & $56.51 \%$ & $86.49 \%$ & $28.88 \%$ & $98.84 \%$ & $58.14 \%$ & $-7.15 \%$ \\
\hline & Galán & $37.90 \%$ & $57.30 \%$ & $89.89 \%$ & $61.06 \%$ & $98.87 \%$ & $65.02 \%$ & $-45.83 \%$ \\
\hline & Confines & $41.70 \%$ & $56.29 \%$ & $84.75 \%$ & $42.76 \%$ & $99.14 \%$ & $61.93 \%$ & $11.95 \%$ \\
\hline & Guapota & $45.07 \%$ & $55.57 \%$ & $84.30 \%$ & $18.70 \%$ & $99.07 \%$ & $54.22 \%$ & $-16.62 \%$ \\
\hline & Chima & $49.42 \%$ & $57.16 \%$ & $90.79 \%$ & $56.83 \%$ & $99.34 \%$ & $57.40 \%$ & $-25.51 \%$ \\
\hline Comunorg & Palmar & $50.17 \%$ & $61.93 \%$ & $93.16 \%$ & $82.07 \%$ & $99.46 \%$ & $51.37 \%$ & $142.59 \%$ \\
\hline Uomunera & $\begin{array}{l}\text { Santa Helena del } \\
\text { Opón }\end{array}$ & $54.11 \%$ & $69.63 \%$ & $92.00 \%$ & $75.00 \%$ & $99.40 \%$ & $83.46 \%$ & $-13.71 \%$ \\
\hline & Contratación & $58.85 \%$ & $65.96 \%$ & $91.80 \%$ & $70.90 \%$ & $99.07 \%$ & $42.60 \%$ & $-31.79 \%$ \\
\hline & Simacota & $59.84 \%$ & $70.37 \%$ & $87.94 \%$ & $62.10 \%$ & $98.20 \%$ & $75.77 \%$ & $-30.28 \%$ \\
\hline & Gambita & $60.00 \%$ & $68.41 \%$ & $90.56 \%$ & $55.88 \%$ & $98.99 \%$ & $73.16 \%$ & $-10.45 \%$ \\
\hline & Guadalupe & $61.19 \%$ & $68.08 \%$ & $89.41 \%$ & $58.27 \%$ & $99.22 \%$ & $48.12 \%$ & $-39.85 \%$ \\
\hline & Suaita & $67.13 \%$ & $73.05 \%$ & $88.90 \%$ & $55.40 \%$ & $99.13 \%$ & $52.27 \%$ & $-21.16 \%$ \\
\hline & Oiba & $69.19 \%$ & $72.52 \%$ & $87.76 \%$ & $56.84 \%$ & $98.96 \%$ & $51.94 \%$ & $27.79 \%$ \\
\hline & Socorro & $76.27 \%$ & $69.67 \%$ & $82.18 \%$ & $45.38 \%$ & $97.62 \%$ & $38.09 \%$ & $28.46 \%$ \\
\hline Promedio & omunera & $51.64 \%$ & $62.68 \%$ & $88.76 \%$ & $56.37 \%$ & $98.99 \%$ & $55.74 \%$ & $-5.17 \%$ \\
\hline Promedio I & epartamento & $55.15 \%$ & $64.40 \%$ & $85.88 \%$ & $64.34 \%$ & $94.95 \%$ & $62.87 \%$ & $-1.41 \%$ \\
\hline
\end{tabular}

Fuente: Cálculos propios en Excel, con base en las ejecuciones presupuestales del DNP y cifras censales.

Vale aclarar dos aspectos de la Tabla 6. Por un lado, la última columna muestra la variación porcentual que experimentó la población de cada municipio entre 1985 a 2017. Por otro, se sombreó de gris a aquellos municipios que tuvieron el ingreso promedio más alto. Es a partir de este que se analiza el porcentaje diferencial de cada municipio frente al municipio que obtuvo el ingreso más alto. 
En ese sentido, para los ingresos medios totales per cápita se presentó que el municipio de Jordán, de la provincia de Guanentá, tuvo el mayor ingreso. Esto se explicó, en parte, por el descenso de la población de $26.32 \%$ a lo largo del periodo (tan solo en 27 municipios del departamento creció la población). En el otro extremo, el ingreso del municipio de Barbosa (el último de la lista) se distanció en un 81.03\% frente al de Jordán; es decir, que por cada peso que tuvo un habitante de Jordán, uno de Barbosa tuvo 0.1897 .

Lo anterior, revela las diferencias entre los municipios de Santander. No obstante, estas se amplían para los otros ingresos, aunque en menor medida para los ingresos corrientes. Para estos el municipio de Barrancabermeja se ubicó en el primer lugar, mientras que El Carmen de Chucurí se distanció, en promedio, un 82.96\% lo que vendría a significar que por cada peso que tuvo un habitante de Barrancabermeja, uno de El Carmen tuvo 0.1704.

Las diferencias se acrecientan para aquellos ingresos que dependen, principalmente, del esfuerzo propio de las administraciones municipales. En el caso de los ingresos tributarios per cápita, nuevamente, Barrancabermeja se ubicó en el primer lugar, mientras que el municipio de Sucre se distanció, en promedio, un 96.61\%. Así que por cada peso que tuvo un habitante de Barrancabermeja, uno de Sucre tuvo 0.0339.

Para el caso de los ingresos no tributarios per cápita Zapatoca obtuvo el primer lugar y, nuevamente, Sucre se instaló en el último lugar a una distancia de $92.36 \%$. Por el lado, del predial el municipio de Floridablanca se posicionó en el primer lugar; mientras que en el extremo opuesto se ubicó El Peñón, con una distancia promedio de 94.7\%; es decir, que este tuvo un 5.3\% del ingreso medio de Floridablanca a lo largo de 1985 a 2017.

En el caso del ICA la diferencia porcentual entre el primero (Barrancabermeja) y el último (San Miguel) fue de 99.9\%, lo que revela inmensas disparidades debido a lo que representa Ecopetrol dentro de la dinámica que genera al interior de Barrancabermeja, que se tradujo que por cada peso que obtuvo un habitante de este municipio, uno de San Miguel tuvo 0.00095.

En síntesis, se observa que la provincia de Mares contribuyó, en mayor medida, a la desigualdad del departamento, seguida de las provincias de Soto, Guanentá, Comunera, Vélez y García-Rovira. Esto se explica porque en la provincia de Mares, en cuatro de los seis tipos de ingresos fiscales, los municipios de Barrancabermeja y Zapatoca ocuparon el primer lugar entre todos los municipios de Santander. Luego el municipio de Floridablanca, de la provincia de Soto, ocupó el primer lugar en el Predial. Y el municipio de Jordán, de la provincia de Guanentá, ocupó el primer lugar en los ingresos totales.

\section{Conclusiones}

Este documento verificó si la desigualdad de los ingresos fiscales de los municipios del departamento de Santander, para el periodo 1985 a 2017, en el marco del proceso de la descentralización fiscal instaurada en Colombia a finales de las últimas dos décadas del siglo XX, se redujo(aumentó) vía transferencias del gobierno nacional central o por el esfuerzo fiscal realizado por los municipios. Lo anterior motivado porque la descentralización pretendía reducir las disparidades regionales, al trasladar el poder de decisión y ejecución de políticas públicas a cargo del nivel central a los territorios. 
Para comprobar lo anterior, se calcularon el índice de Theil y el coeficiente de Gini de los ingresos fiscales per cápita, deflactados a precios de 2015, con información proveniente de las ejecuciones presupuestales que los municipios reportan al DNP. En términos generales, los resultados permiten señalar que la desigualdad de los ingresos fiscales disminuyó, pero en mayor medida en los ingresos totales y corrientes, por lo cual se deduce que el descenso se dio, especialmente, por las transferencias del gobierno nacional central.

La deducción anterior se confirmó al dividir el análisis entre 1985-1999 y 19992017. De hecho, la desigualdad descendió para ambos periodos en los ingresos totales y corrientes. No obstante, para los ingresos que dependen del esfuerzo fiscal municipal (Tributarios, Predial, ICA y No tributarios) la desigualdad aumentó para el primer periodo; mientras para el segundo disminuyó por los ajustes normativos dirigidos a sanear las finanzas locales y reducir la dependencia de los territorios de las transferencias del orden nacional.

Usando el Theil se realizó un análisis sobre la desigualdad a nivel interprovincial (al interior de los municipios que conforman las distintas provincias) e intraprovincial (entre las provincias del departamento). Nuevamente, se confirmó que el mayor descenso de la desigualdad interprovincial se presentó en los ingresos totales y corrientes; mientras que en los otros fue menor. Para la desigualdad intraprovincial se redujo para los ingresos totales, corrientes y tributarios, ratificando que la reducción se dio por las trasferencias del gobierno central.

Valga decir que, en promedio, a nivel interprovincial, el 81.2\% de la desigualdad de los seis tipos de ingresos fiscales per cápita se explicó por las dinámicas internas de los municipios de las provincias; mientras que, el 18.8\% restante de la desigualdad se manifestó por la interacción entre las seis provincias del departamento. Además, la provincia de Mares contribuyó, en mayor medida, a la desigualdad del departamento, seguida de las provincias de Soto, Guanentá, Comunera, Vélez y García-Rovira.

Las conclusiones esbozadas, relacionadas con el comportamiento de los ingresos fiscales per cápita de los municipios de Santander, se sitúan en un horizonte de largo plazo, lo que permite determinar que aunque, en términos generales, se redujo la desigualdad; es necesario prestar atención a las particulares y, en algunos casos, alarmantes disparidades entre municipios y provincias que, probablemente, ha llevado a que los habitantes de los municipios con menores ingresos fiscales per cápita migren a otros territorios en busca de mejores oportunidades socioeconómicas.

Entonces, se deduce que al interior de Santander hay marcadas disparidades, lo que se refleja en menores niveles de desarrollo relativo para la gran mayoría de municipios del departamento. De modo que, aunque a nivel general se presentó una reducción de la desigualdad, al mirar con más detalle las desigualdades intermunicipales y provinciales se obtuvo que las reducciones se dieron, especialmente, por las trasferencias del gobierno central y la dinámica económica de los grandes municipios del departamento.

Lo anterior, deja un panorama oscuro para los pequeños municipios al ser incapaces de generar dinámicas económicas que las hagan depender menos de las fuentes de recursos del orden nacional. Por ende, en lugar de tener mayor autonomía o des- 
centralización fiscal, lo que se tiene en la realidad es una centralización fiscal, que es justo lo que se quiso revertir con las disposiciones fiscales de la Constitución Política. Esto ameritaría adelantar futuras investigaciones en otros departamentos del país con el fin de revisar si esta conclusión se extiende a otros territorios.

\section{REFERENCIAS}

Arrow, K. (1969). The organization of economic activity: issues pertinent to the choice of market versus nonmarket allocation. The analysis and evaluation of public expenditure: the PPB system, 1, 59-73. http://citeseerx.ist.psu.edu/viewdoc/ summary?doi=10.1.1.324.971

Asamblea de Boyacá. (14 de mayo de 2019). Por la cual se autoriza al gobernador de boyacá y al gerente del instituto financiero de boyaca, para la enajenación de la propiedad accionariaque posee el infiboy en la sociedad acerias paz del rio s.A., Y se dictan otras disposiciones. [Ordenanza 10]. Disponible en http://www. asamblea-boyaca.gov.co/proyectos-de-ordenanzas/ordenanza-no-010-de-2019

Bacallao, J. (2007). Indicadores basados en la noción de entropía para la medición de las desigualdades sociales en salud. Revista cubana de salud pública, 33(4). http://dx.doi.org/10.1590/S0864-34662007000400007

Banco Mundial. (1998). Descentralización en Colombia. Nuevos desafíos. [RE3-98002]. Washington, D.C.: World Bank.

Betancurt et al. (2002). Observaciones a la Ley del Sistema General de Participaciones. Economía Colombiana, (289), 58-69. Disponible en https://www.contraloria.gov.co/web/guest/resultados/publicaciones/revista-economia-colombiana

Boisier, S. (1987). Procesos de descentralización y de desarrollo regional en el escenario actual de América Latina. En, Ensayos sobre descentralización y desarrollo regional [LC/IP/G. 42-P] (pp. 79-96). Santiago de Chile: NU, CEPAL, ILPES.

Bonet, J. y Meisel, A. (2007). Polarización del ingreso per cápita departamental en Colombia, 1975 -2000. En, E. Rodríguez y L. Vallejo (Comp.), Modelos de desarrollo y economía regional (pp. 170-199). Tunja: CENES, UPTC.

Brennan, G. \& Buchanan, J. (1980). The Power to Tax: Analytical Foundations of a Fiscal Constitution. Cambridge: Cambridge University Press.

Rojas, C. (2016). Labor flexibilization in Colombia. Juridicas CUC, 12(1), 17-29. Disponible en https://revistascientificas.cuc.edu.co/juridicascuc/article/view/1113

Casas, J. (2017). Implicaciones de los acuerdos del Fondo Monetario Internacional sobre la pobreza en Colombia. Económicas CUC, 38(1), 9-36. http://dx.doi. org/10.17981/econcuc.38.1.01

Chumaceiro, A. y Hernández, J. (2012). La legislación tributaria venezolana como promotora de la responsabilidad social empresarial. Revista OIKOS, 16(33), 53-68. Disponible en http://ediciones.ucsh.cl/ojs/index.php/Oikos/article/view/1041/982

Currie, L. (1951). Bases de un programa de fomento para Colombia. Bogotá, D.C.: Banco de la República.

De la Torre, M. (2018). Utilización del sector financiero para el lavado de dinero: perspectiva desde la legislación ecuatoriana. Jurídicas CUC, 14(1), 145-166. http://dx.doi.org/10.17981/ juridcuc.14.1.2018.7 
Flores, M. (2002). Federalismo fiscal y asignación de competencias: una perspectiva teórica. Economía, sociedad y territorio, 3(11), 387-407. https://doi.org/10.22136/ est002002345

FMI. (2001). Manual de Estadísticas de Finanzas Públicas. Washington D.C.: FMI. Frège, X. (1986). La décentralisation. [Colección: Repères $\left.N^{\circ} 44\right]$. París: La Découverte.

Garay, L. (2004). Colombia: estructura industrial e internacionalización 1967-1996. Bogotá, D.C.: DNP.

Giraldo, C. (2005). Finanzas Públicas en América Latina: la economía política. (3 $E d$.), Bogotá, D.C.: Desde abajo.

Guerrero, P. (2014). Finanzas públicas y desigualdad fiscal en los municipios de Boyacá, 1985-2010. Apuntes del CENES, 33, 177-222. https://doi. org/10.19053/22565779.2908

Guerrero, P. (2009). Descentralización y finanzas públicas en el departamento de Boyacá: un estudio cuantitativo y analítico 1984-2007. [Tesis magistral]. Universidades Nacional de Colombia y Pedagogicay Tecnologica de Colombia, Tunja, Colombia. Recuperado de https://es.scribd.com/document/91821326/ DESENTRALIZACION-Y-FINANZAS-PUBLICAS-EN-EL-DEPARTAMENTO-DE-BOYACA-UN-ESTUDIO-CUANTITATIVO-Y-ANALITICO-1984-2

Gutiérrez, E. (1990). La crisis laboral y el futuro del mundo del trabajo. En, E. Gutiérrez, La ocupación del futuro. Flexibilidad y desreglamentación laboral. Caracas: Fundación Friedrich Ebert-Nueva Sociedad.

Heilbroner, R. L. \& Milberg, W. S. (1995). The crisis of vision in modern economic thought. Cambridge: Cambridge University Press.

Hernández, H. (2016). La descentralización administrativa en Colombia: un reto inconcluso y un desafío para el posconflicto. IUSTA, 2(45), 81-106. https://doi. org/10.15332/s1900-0448.2016.0045.04

Hernández, A. y Barreto, L. H. (2018). Descentralización y finanzas territoriales. Cuadernos Fedesarrollo, 59. [Online]. Disponible en http://hdl.handle. net/11445/3555

Hernández, J. y Chumaceiro, A. (2018). Una discusión epistemológica sobre gestión de la participación ciudadana. Revista Opción, 34(87), 856-883. Disponible en https://produccioncientificaluz.org/index.php/opcion/article/view/23900

Iregui, A. M., Ramos, J. y Saavedra, L. A. (2001). Análisis de la descentralización fiscal en Colombia. Bogotá, D.C.: Banco de la República.

Lora, E. (2008). Técnicas de medición económica. Metodología y aplicaciones en Colombia. (4 ed.). Bogotá, D.C.: AlfaOmega.

Martínez, A. (2006). Determinantes del PIB per cápita de los departamentos colombianos 1975-2003. [Archivos de Economía]. Bogotá, D.C.: Banco de la República.

Musgrave, R. (1959). The Theory of Public Finance. New York: McGraw Hill.

Oates, W. (1972). Fiscal Federalism. Madrid: Institute of Fiscal Studies.

Paredes-Chacín, J. (2017). Planificación financiera ante la perspectiva organizacional en empresas cementeras del estado Zulia-Venezuela. Económicas CUC, 38(1), 105-132. https://doi.org/10.17981/econcuc.38.1.05 
Paz, A., Harris, J. y Franco, F. (2016). Responsabilidad social gestión compartida con el emprendedor social en empresas mixtas del sector petrolero. Económicas CUC, 37(2), 47-68. https://doi.org/10.17981/econcuc.37.2.2016.03

Reales, A. (2016). La democracia representativa en el marco de los derechos humanos en Colombia. Jurídicas CUC, 12(1), 9-16. Disponible en https://revistascientificas.cuc.edu.co/juridicascuc/article/view/1112

República de Colombia. Asamblea Constituyente. (1991). Constitución política de Colombia. Bogotá, D.C.: Leyer.

República de Colombia. Congreso de la República. (11 de julio de 2007). Por el cual se reforman los artículos 356 y 357 de la Constitución Política. [Acto legislativo 4]. Diario Oficial No. 46.686. Disponible en http://svrpubindc.imprenta.gov.co/ diario/

República de Colombia. Congreso de la República. (27 de diciembre de 2007). Por la cual se desarrollan los artículos 356 y 357 de la Constitución Política y se dictan otras disposiciones. [Ley 1176]. Diario Oficial No. 46.854. Disponible en http://svrpubindc.imprenta.gov.co/diario/

República de Colombia. Congreso de la República. (30 de julio de 2001). Por medio del cual se modifican algunos artículos de la Constitución Política. [Acto legislativo 1]. Diario Oficial No. 44.506. Disponible en http://svrpubindc.imprenta. gov.co/diario/

República de Colombia. Congreso de la República. (21 de diciembre de 2001). Por la cual se dictan normas orgánicas en materia de recursos y competencias de conformidad con los artículos 151, 288, 356 y 357 (Acto Legislativo 01 de 2001) de la Constitución Política y se dictan otras disposiciones para organizar la prestación de los servicios de educación y salud, entre otros. [Ley 715]. Diario Oficial No 44.654. Disponible en http://svrpubindc.imprenta.gov.co/diario/

República de Colombia. Congreso de la República. (6 de octubre de 2000). Por la cual se reforma parcialmente la Ley 136 de 1994, el Decreto Extraordinario 1222 de 1986, se adiciona la Ley Orgánica de Presupuesto, el Decreto 1421 de 1993, se dictan otras normas tendientes a fortalecer la descentralización, y se dictan normas para la racionalización del gasto público nacional. [Ley 617]. Diario Oficial No. 44.188. Disponible en http://svrpubindc.imprenta.gov.co/diario/

República de Colombia. Congreso de la República. (12 de agosto de 1993). Por la cual se dictan normas orgánicas sobre la distribución de competencias de conformidad con los artículos 151 y 288 de la Constitución Política y se distribuyen recursos según los artículos 356 y 357 de la Constitución Política y se dictan otras disposiciones. [Ley 60]. Diario Oficial No. 40.987. Disponible en http:// svrpubindc.imprenta.gov.co/diario/

República de Colombia. Congreso de la República. (18 de diciembre de 1990). Por la cual se dictan normas sobre catastro e impuestos sobre la propiedad raíz, se dictan otras disposiciones de carácter tributario, y se conceden unas facultades extraordinarias. [Ley 44]. Diario Oficial No. 39.607. Disponible en http://svrpubindc.imprenta.gov.co/diario/ 
Restrepo, D. (Coord.) (2006). Historias de descentralización: transformación del régimen político y cambio en el modelo de desarrollo América Latina, Europa y EUA. Bogotá, D.C., Colombia: Universidad Nacional de Colombia. Disponible en http://www.fce.unal.edu.co/centro-editorial/catalogo/1838

Rodríguez, A y Adala, B. (2005). La ineficiencia económica en los procesos de descentralización. Revista Ekonomiaz, 58(1), 146-175. Disponible en https://www. euskadi.eus/web01-a2reveko/es/k86aEkonomiazWar/ekonomiaz/inicio

Sagawe, T. (2006). Niveles supramunicipales y niveles intermedios en la construcción de los Estados modernos. En, CID, Historias de Descentralización (pp. 6995). Bogotá, D.C.: Universidad Nacional de Colombia.

Samuelson, P. A. (1954). The pure theory of public expenditure. The review of economics and statistics, 36(4), 387-389. Available from https://www.ses.unam.mx/ docencia/2007II/Lecturas/Mod3_Samuelson.pdf

Sánchez, F. \& Núñez, J. (2000). Geography and economic development: a municipal approach for Colombia. Planeación y Desarrollo, 31(3/4), 379-451. https://doi. org/10.2139/ssrn.1814677

Sen, A. (1979). Equality of what? In: S. McMurrin, Tanner Lectures on Human Values [Volume 1]. Cambridge: Cambridge University Press.

Tiebout, C. M. (1956). A pure theory of local expenditures. Journal of political economy, 64(5), 416-424. Available from https:/fbaum.unc.edu/teaching/PLSC541_ Fall08/tiebout_1956.pdf

Tobar, N (2011). Situación fiscal de los municipios de Boyacá y el impacto de la ley 617 de 2000: 1985-2008. [Doctoral dissertation]. Universidad Nacional de Colombia, Bogotá, D.C., Colombia.

Villa, G. (2005). Colombia: Gasto público social regional 1997-2003, con breves comparaciones internacionales. [Ensayos Sobre Economía Regional, ESER 26]. Bogotá, D.C.: Banco de la Republica de Colombia. Disponible en https://econpapers. repec.org/paper/bdreserdt/26.htm

Viloria, J. (2001). Descentralización en el Caribe colombiano: las finanzas departamentales en los noventas. [Documentos de Trabajo sobre Economía Regional y Urbana 002283]. Bogotá, D.C.: Banco de la República. https://doi.org/10.32468/ dtseru. 20

Younes, D. (2012). Las reformas del Estado y de la administración pública. Bogotá, D.C.: Instituto de Estudios del Ministerio Público.

\section{BIODATA}

Betty Cecilia Barajas Ibáñez es Administradora publica de la ESAP. Sus temas de interés investigativo se encuentran en el marco de las finanzas públicas territoriales. https://orcid.org/0000-0002-2128-2794

Julián Augusto Casas Herrera es economista y especialista en Finanzas de la UPTC, Magíster en ciencias económicas de la Universidad Nacional de Colombia. Los interesantes investigativos giran alrededor de las políticas públicas y sociales. https://orcid.org/0000-0001-6606-5059 